\title{
The Ins and Outs of Aurora B Inner Centromere Localization
}

\author{
Sanne Hindriksen, Susanne M. A. Lens ${ }^{*}$ and Michael A. Hadders \\ Oncode Institute, Center for Molecular Medicine, University Medical Center Utrecht, Utrecht University, Utrecht, Netherlands
}

Error-free chromosome segregation is essential for the maintenance of genomic integrity during cell division. Aurora $\mathrm{B}$, the enzymatic subunit of the Chromosomal Passenger Complex (CPC), plays a crucial role in this process. In early mitosis Aurora B localizes predominantly to the inner centromere, a specialized region of chromatin that lies at the crossroads between the inter-kinetochore and inter-sister chromatid axes. Two evolutionarily conserved histone kinases, Haspin and Bub1, control the positioning of the CPC at the inner centromere and this location is thought to be crucial for the CPC to function. However, recent studies sketch a subtler picture, in which not all functions of the $\mathrm{CPC}$ require strict confinement to the inner centromere. In this review we discuss the molecular pathways that direct Aurora B to the inner centromere and deliberate if and why this specific localization is important for Aurora B function.

OPEN ACCESS

Edited by:

Sabine Elowe

Laval University, Canada

Reviewed by:

Song-Tao Liu,

University of Toledo, United States

Mar Carmena,

University of Edinburgh,

United Kingdom

${ }^{*}$ Correspondence:

Susanne M. A. Lens

s.m.a.lens@umcutrecht.n!

Specialty section:

This article was submitted to

Cell Growth and Division,

a section of the journal

Frontiers in Cell and Developmental

Biology

Received: 10 October 2017 Accepted: 04 December 2017 Published: 22 December 2017

Citation:

Hindriksen S, Lens SMA and Hadders MA (2017) The Ins and Outs of Aurora B Inner Centromere

Localization.

Front. Cell Dev. Biol. 5:112. doi: 10.3389/fcell.2017.00112
Keywords: Aurora B, Chromosomal Passenger Complex, Haspin, Bub1, Shugoshin, chromosome segregation, centromere, mitosis

\section{INTRODUCTION}

The segregation of chromosomes during mitosis is perhaps the most dramatic event of the cell cycle. The underlying forces that mediate the division of our DNA must be tightly controlled to ensure accurate distribution of the genomic content between the newly formed daughter cells. The mitotic kinase Aurora B plays a crucial role in this process. Aurora B is the enzymatic component of a larger protein assembly, termed the Chromosomal Passenger Complex (CPC). In mitosis, the CPC is concentrated at the inner centromere, a highly specialized region on the chromatin where the intersister chromatid axis and the inter-kinetochore axis intersect (Figure 1). Concentrating the CPC at the centromere region is considered crucial for its function as it places Aurora B in close proximity to its substrates on kinetochores. At the same time, its confinement to the inner centromere is thought to allow discrimination between spatially separated substrates (Liu et al., 2009; Welburn et al., 2010). Multiple regulatory networks involving multiple mitotic kinases determine the site of $\mathrm{CPC}$ activity. Intriguingly, these networks are themselves centered on Aurora B activity and thus involve multiple feedback circuits. In this review, we discuss the molecular determinants that guide the CPC toward the (inner) centromere and deliberate on the relevance of this specific localization for Aurora B function.

\section{THE CHROMOSOMAL PASSENGER COMPLEX}

In addition to Aurora B, the CPC consists of the accessory subunits Borealin, Survivin, and INCENP. The complex can be divided into two functional modules that are bridged by INCENP. The first module consists of Borealin and Survivin, which bind to the N-terminal region of INCENP (referred to as the CEN module) and together control the localization of the CPC (Klein et al., 2006; Jeyaprakash et al., 2007; Carmena et al., 2012). The second module harbors the activity of the CPC 
and consists of Aurora $\mathrm{B}$ associated with a region at the $\mathrm{C}$ terminus of INCENP (known as the IN-box). The interaction between Aurora B and the IN-box not only links Aurora B to the CPC but is also required for its full kinase activity (Bishop and Schumacher, 2002; Honda et al., 2003; Sessa et al., 2005).

The CPC is first observed in the nucleus in late $S$ phase with expression peaking in G2/M phase (Carmena et al., 2012). Upon entry into mitosis all CPC subunits can be observed along the length of the chromosome arms although their localization quickly becomes restricted to centromeres, specifically at the inter-sister chromatid region referred to as the inner centromere (Figure 1). At anaphase onset the CPC translocates to the central spindle where Aurora B activity contributes to cytokinesis (Carmena et al., 2012). In this review, however, we will only focus on the role of the CPC at the inner centromere.

We stress the use of consistent terminology when describing the various pools of proteins at the centromere region. First, we define the inner centromere as the intersection of the intersister chromatid axis and the inter-kinetochore axis (Figure 1). Proteins found at the inner centromere include the cohesin complex, the CPC, Shugoshin 1/2 (Sgo1/2), Haspin and the phospho-mark H3T3ph, which are typically observed as a single focus in between the kinetochores (Figure 1). Second, we define the region located more outward along the inter-kinetochore axis as the kinetochore-proximal centromere. Proteins found at the kinetochore-proximal centromere include CENP-A, CENP-B, Sgo1/2 and the phospho-mark H2AT120ph, which are observed as two foci adjacent to kinetochores (Figure 1). The final region along the inter-kinetochore axis consists of the kinetochores, large protein structures assembled on CENP-A containing chromatin. The kinetochore can further be divided into the inner kinetochore, consisting of the CCAN (Constitutively Centromere Associated Network) proteins and the outer kinetochore, which includes the KMN network (comprising Knl1, the Mis12 complex and the NDC80 complex), Bub1 and Mps1. These proteins are also observed as two foci located further apart along the interkinetochore axis (Figure 1). Confusion arises as proteins are often labeled as belonging to "a kinetochore pool" based solely on the observation of two distinct foci. While it may be difficult to discriminate between the kinetochore-proximal centromere and the kinetochores experimentally we believe the distinction is important when discussing the spatial regulation of CPC function.

\section{HOW IS INNER CENTROMERE LOCALIZATION OF THE CPC REGULATED?}

\section{The Two Recruitment Arms That Control Inner Centromere Localization of the CPC}

Inner centromere localization of the CPC depends on the activity of two histone kinases, Haspin and Bub1, which phosphorylate histone $\mathrm{H} 3$ on threonine $3(\mathrm{H} 3 \mathrm{~T} 3 \mathrm{ph})$ and histone $\mathrm{H} 2 \mathrm{~A}$ on threonine 120 (H2AT120ph) respectively. These phospho-marks are believed to function as the centromeric receptors for the CPC (Figure 2). The CPC can indeed bind directly to H3T3ph via Survivin and depletion of Haspin or inhibition of Haspin kinase activity results in dispersion of the CPC over the chromosome arms (Kelly et al., 2010; Wang et al., 2010, 2012; Yamagishi et al., 2010; De Antoni et al., 2012). Moreover, mutations in the BIR domain of Survivin that abrogate H3T3ph binding result in a similar phenotype (Lens et al., 2006; Yue et al., 2008; Kelly et al., 2010; Wang et al., 2010; Yamagishi et al., 2010). However, while the CPC becomes largely dispersed over the chromatin in the absence of Haspin activity, a residual centromeric pool of the CPC adjacent to kinetochores has been observed (Bekier et al., 2015). As of yet it is unclear what controls the localization of the CPC in the absence of Haspin activity, however, it is tempting to speculate the involvement of Bub1 and Sgo1/2, as the CPC appears to co-localize with H2AT120ph at the kinetochore-proximal centromeres in this case (Bekier et al., 2015). Alternatively, the two foci may represent a kinetochore pool of the CPC, as previously suggested by DeLuca et al. based on their observation of an active pool of Aurora B at the kinetochores, using phospho-specific antibodies (DeLuca et al., 2011; Caldas et al., 2013).

The interaction between H2AT120ph and the CPC requires the Shugoshin paralogs, Sgo1 and Sgo2. Sgo1 and Sgo2 localize to centromeres in a Bub1 dependent fashion, where they play a crucial role in protecting centromeric cohesin from Wapland Plk1-dependent removal during prophase (Figure 3A) (Salic et al., 2004; Tang et al., 2004; Kitajima et al., 2005, 2006; McGuinness et al., 2005; Gandhi et al., 2006; Kueng et al., 2006; Tanno et al., 2010; Haarhuis et al., 2013; Tedeschi et al., 2013). Sgo1 and Sgo2 directly interact with both H2AT120ph and the CPC, suggesting they may serve as adaptors that control centromere localization of the CPC (Kawashima et al., 2007, 2010; Tsukahara et al., 2010; Yamagishi et al., 2010; Liu et al., 2015; Baron et al., 2016). Indeed, depletion of Sgo1 and Sgo2 results in a marked decrease in centromere levels of the CPC, similar to what is observed for the depletion or inhibition of Bub1 (Yamagishi et al., 2010; Baron et al., 2016).

It is clear that Haspin and Bub1, in conjunction with Sgo1 and Sgo2, cooperate to define a unique chromatin environment that supports recruitment of the CPC toward the inner centromere. Major advances in the past decade have resulted in a picture that suggests that Haspin and Bub1 exert their control over the $\mathrm{CPC}$ by regulating two distinct axes along mitotic chromosomes: while Haspin-H3T3ph facilitates recruitment of the CPC toward the inter-sister chromatid axis the Bub1H2AT120ph-Sgo1/2 pathway restricts the inter-sister chromatid pool of the CPC to centromeres. Together, these pathways form an evolutionarily conserved mechanism that defines the inner centromere (Table 1) (Yamagishi et al., 2010).

\section{Haspin, Н3T3ph and the Inter-sister Chromatid Axis}

Clearly, the mitotic kinase Haspin plays a crucial role in regulating CPC localization (Kelly et al., 2010; Wang et al., 2010). By phosphorylating H3T3 it generates a receptor that directly recruits the CPC via Survivin. This raises the question how H3T3 phosphorylation becomes enriched at the inner centromere. The data so far point to a complex regulatory network that involves 


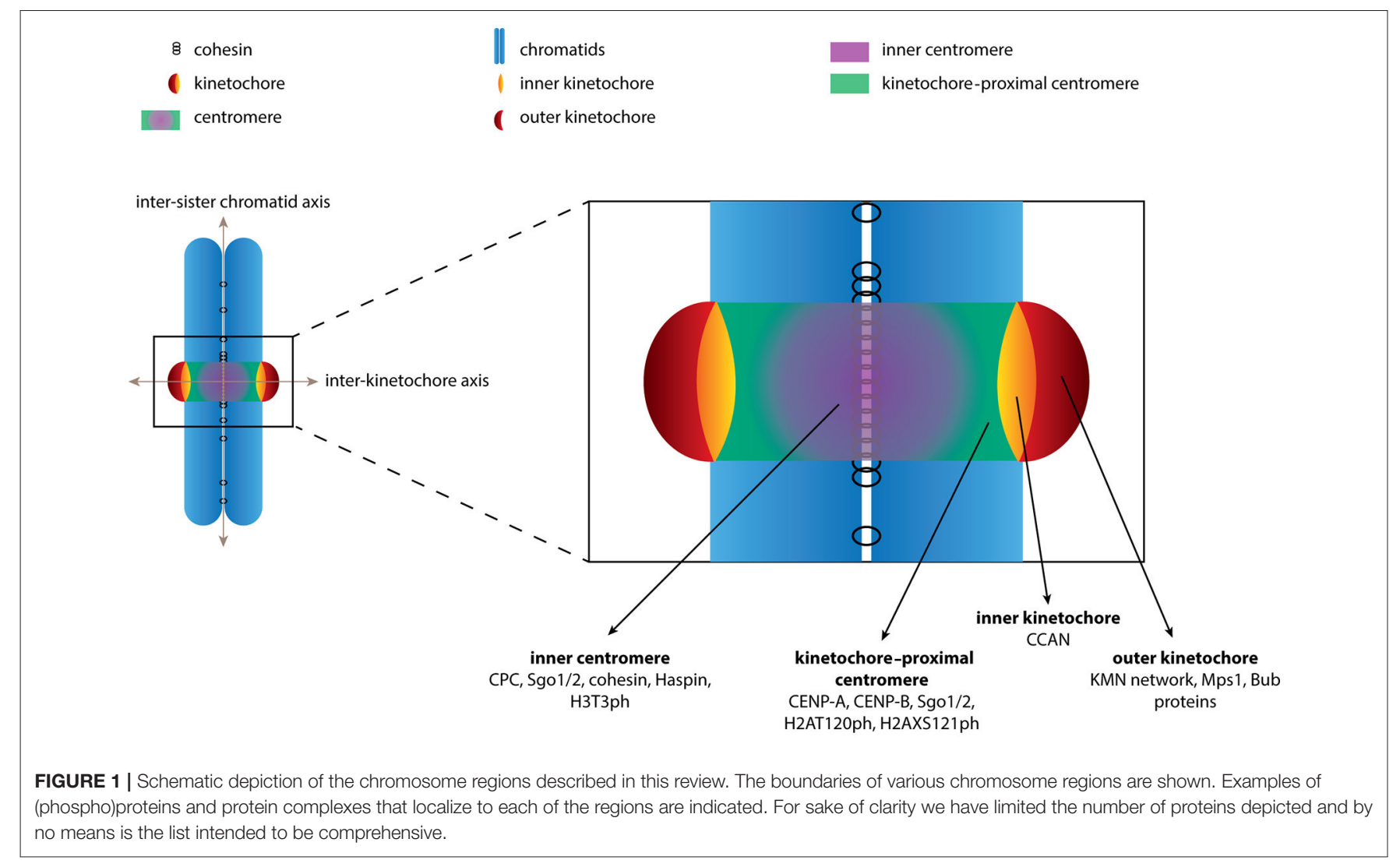

the regulation of Haspin localization and kinase activity, the spatial control of the H3T3ph counteracting phosphatase Protein Phosphatase $1 \gamma(\mathrm{PP} 1 \gamma)$, and perhaps the presence of other epigenetic marks within the $\mathrm{H} 3$ tail that changes its ability to serve as a substrate for Haspin.

\section{Regulation of Haspin Localization}

Defining the native localization of Haspin has been hampered by technical challenges. Available antibodies do not allow detection of endogenous Haspin by immunofluorescence, suggesting that the protein is likely expressed at very low levels (Higgins, 2001b). Indeed, endogenous Haspin tagged with YFP is observed at very low levels on mitotic chromatin (Hindriksen et al., 2017). This localization pattern appears similar to what has been observed for overexpressed GFP-Haspin (Dai et al., 2005). More detailed analysis of chromosome spreads has revealed that ectopically expressed GFP-Haspin is concentrated at the inner centromere, coinciding with H3T3ph and the CPC (Dai et al., 2005; Yamagishi et al., 2010; Yoshida et al., 2016; Goto et al., 2017). Multiple factors contribute to the defined localization of Haspin at the inner centromere. First, Haspin directly interacts with the cohesin-associated proteins Pds5A/B (Yamagishi et al., 2010; Carretero et al., 2013; Goto et al., 2017; Zhou et al., 2017). The cohesin complex is established along the entire length of the inter-sister chromatid axis during $S$ phase (Figure 1). However, the majority is removed early in mitosis. This process is termed the prophase pathway and depends on the activity of Wapl and Plk1 (Figure 3A) (Hauf et al., 2005; Haarhuis et al., 2014).
Centromeres are resistant to the cohesin removing activity of Wapl and Plk1 due to the presence of Sgol that is bound to the phosphatase PP2A, thereby keeping sister chromatids together until anaphase onset (Haarhuis et al., 2014). Thus, through the progressive removal of cohesin complexes from the chromosome arms, the prophase pathway is thought to contribute to the concentration of the cohesin complex, including Pds5A/B and Haspin, at the inner centromere (Watanabe, 2010). In line with this model, interfering with the prophase pathway, through depletion of Wapl, results in a more dispersed localization of the CPC along the chromosome arms (Haarhuis et al., 2013; Tedeschi et al., 2013). Interestingly, recent work has demonstrated that Haspin and Wapl compete for the same binding site on Pds5B. Therefore, Haspin also directly contributes to centromeric cohesion protection (Goto et al., 2017; Zhou et al., 2017).

In addition, recent work has highlighted a role for Topoisomerase II (TopoII) in Haspin recruitment. TopoII plays a central role in the architecture of mitotic chromatin but also resolves topological problems, for example those that arise during DNA replication (Nitiss, 2009). TopoII displays a distinct axial localization along the chromosomes, and also accumulates at centromeres where its activity resolves topologically linked sister chromatids, or catenanes, prior to and during early anaphase (Earnshaw and Heck, 1985; Rattner et al., 1996; Christensen et al., 2002; Tavormina et al., 2002; Hudson et al., 2003; Kireeva et al., 2004; Lee and Bachant, 2009; Samejima et al., 2012; Hengeveld et al., 2015). Depletion of TopoII in Drosophila melanogaster $(D m)$ S2 cells was shown to result in delocalization of the 


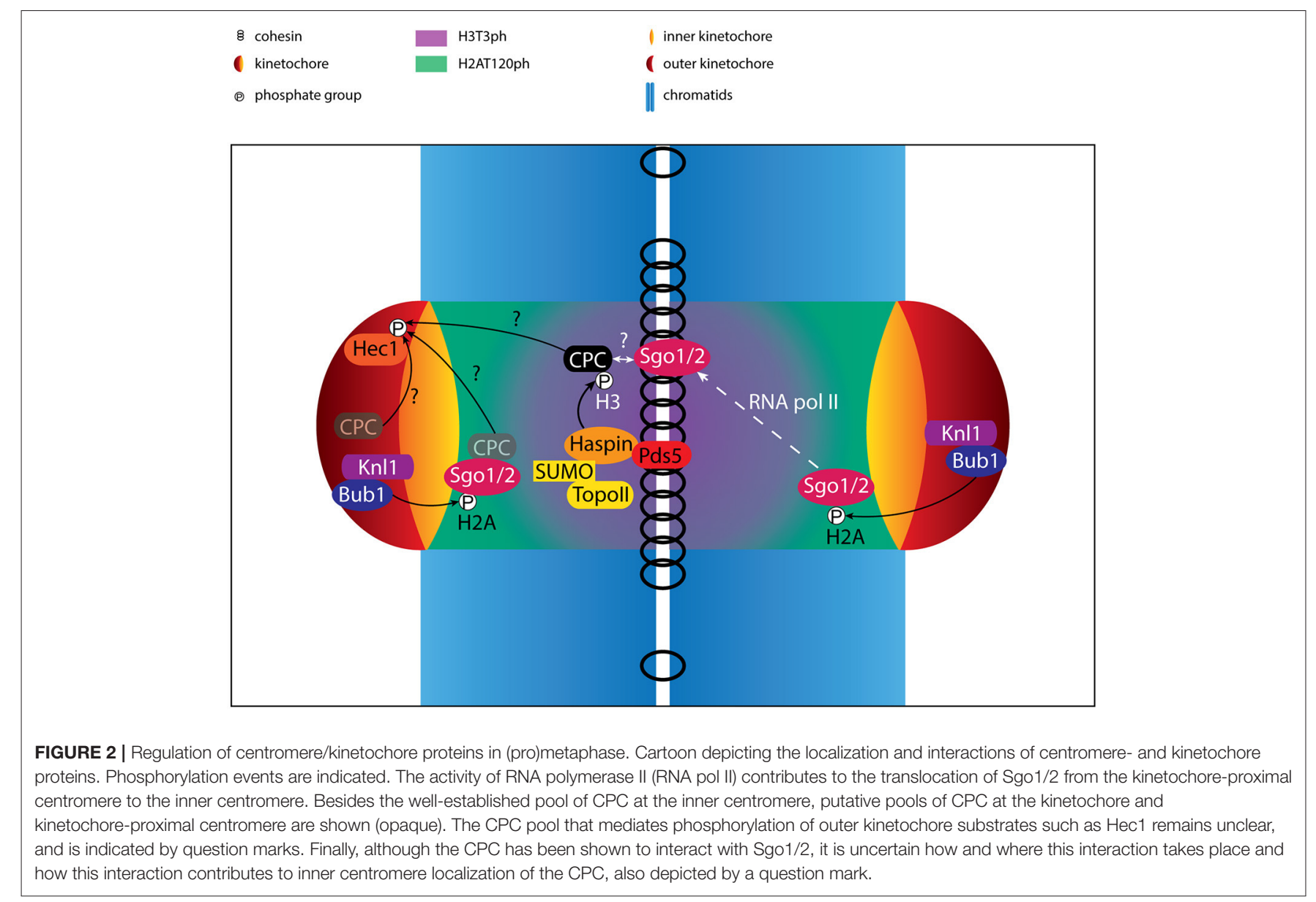

CPC to kinetochore-proximal centromeres, reminiscent of the residual pool of the CPC observed upon Haspin inhibition in human cells (Coelho et al., 2008; Bekier et al., 2015). In line with this, recent work in yeast and frogs has demonstrated that the altered localization of the CPC upon TopoII depletion is likely due to disruption of Haspin recruitment to chromatin. Recruitment of Haspin does not require TopoII catalytic activity but instead depends on the modification of the TopoII Cterminal domain (CTD) with a Small Ubiquitin-like MOdifier (SUMO) (Edgerton et al., 2016; Yoshida et al., 2016; Goto et al., 2017). SUMOylation of TopoII is required for TopoII enrichment at centromeres during mitosis (Azuma et al., 2003, 2005; DíazMartínez et al., 2006; Dawlaty et al., 2008). Haspin contains a SUMO interacting motif (SIM) that binds to SUMOylated TopoII. Additionally, this interaction strongly depends on phosphorylation of Haspin by Cdk1. It is unclear if TopoII also contributes to Haspin recruitment in human cells. However, the presence of a SIM is conserved in human Haspin and SUMOylation is high at centromeres during mitosis (Zhang et al., 2008).

So far the data indicate that cohesin-Pds5A/B and TopoIISUMO collaborate to control the localization of Haspin to the inner centromere. This suggests that coincidence detection, the requirement for simultaneous binding of Haspin to Pds5A/B and SUMO-conjugated TopoII, may serve to restrict Haspin localization to the inner centromere. At the same time the prophase pathway likely contributes to this process through the removal of cohesin from the chromosome arms.

While these data provide an explanation for the observed enrichment of Haspin around the centromeres during mitosis, it should be noted that both in and out of mitosis most of Haspin is associated with chromatin along the entire chromosomal arms, where the levels of cohesin and SUMO conjugated TopoII are low. This argues that alternative factors may further contribute to chromatin association of Haspin. Alternatively, chromatin association of $\mathrm{Pds} 5 \mathrm{~A} / \mathrm{B}$ may be differentially regulated from cohesin. Pds5A/B do not belong to the core components of the cohesin complex and several studies indeed indicate that $\mathrm{Pds} 5 \mathrm{~A} / \mathrm{B}$ behavior on chromatin differs from that of the cohesin core. Analysis of conditional Scc1 knockout (KO) cells revealed a strong concomitant decrease in chromatin associated SMC1, SMC3, SA1 and SA2, the other core components of the cohesin complex (Ohta et al., 2016). However, chromatin levels of the cohesin associated regulatory factors Pds5A and Wapl did not decrease to similar extents and Pds5B levels remained unchanged. In line with these results, depletion of Sccl results in dispersion, but not loss, of H3T3ph over the length of the chromosome arms (Yamagishi et al., 2010). Taken together, the 

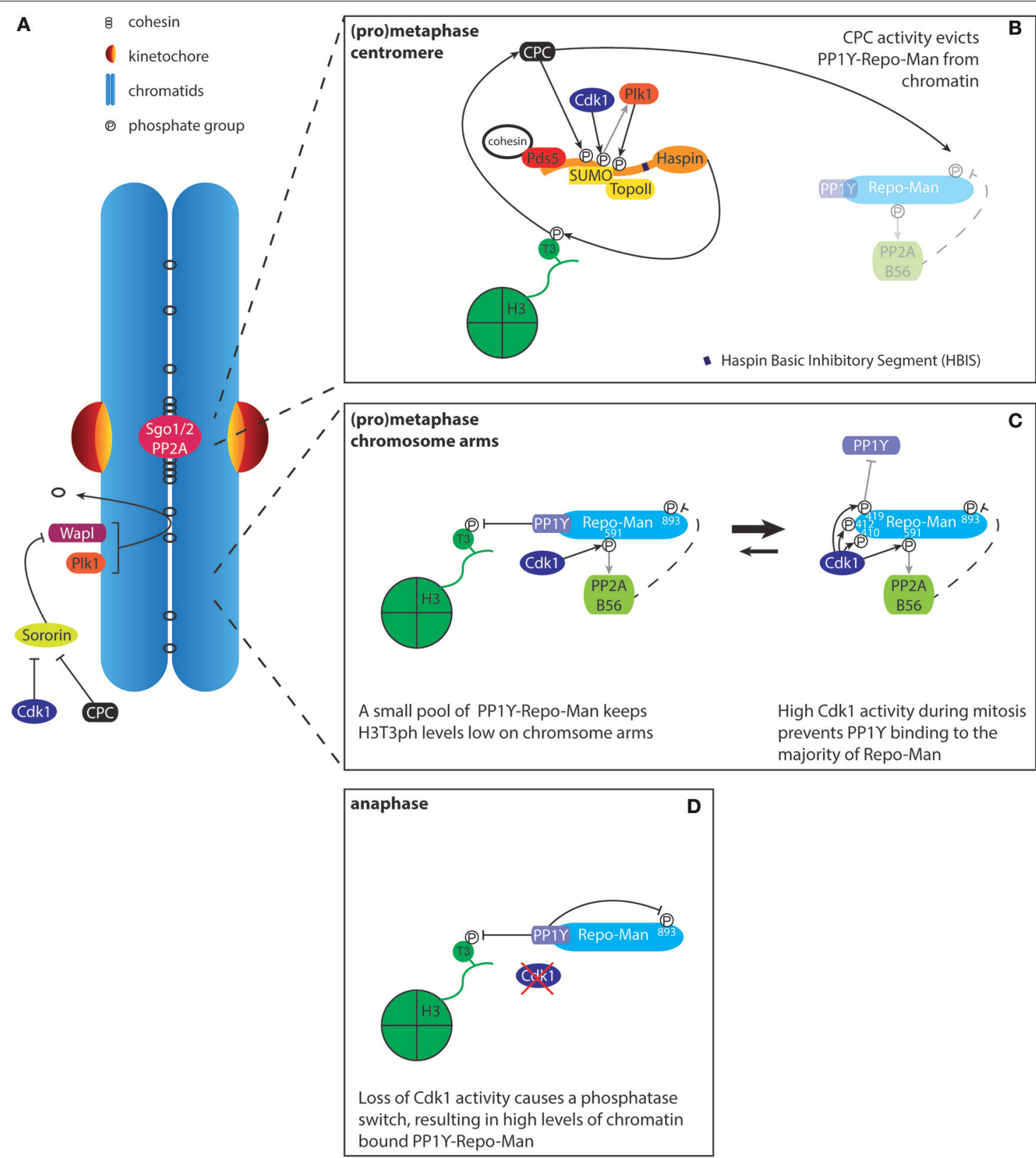

FIGURE 3 | Regulation of histone H3T3 phosphorylation by Haspin and PP1Y-Repo-Man. (A) The prophase pathway removes cohesin from the chromosome arms. Sororin binds to the cohesin complex and this interaction is required for maintaining stable cohesion. During mitosis, Plk1 phosphorylates the cohesin subunit SA2 while Cdk1 and Aurora B phosphorylate Sororin. This results in the release of Sororin from cohesin, leading to the Wapl dependent removal of cohesin from chromatin Centromeres are protected against the prophase pathway through recruitment of Sgo1/2-PP2A. The recruitment of Sgo1-PP2A results in de-phosphorylation of SA2 and Sororin, rendering the centromeric cohesin complexes resistant to Wapl activity. Effectively, this results in the concentration of cohesin/Pds5A/B and thus Haspin at centromeres, thereby contributing to the defined localization of the $\mathrm{CPC}$ at the inner centromere. (B) The cohesin-associated protein Pds5A/B, in conjunction with SUMOylated Topoisomerase II (Topoll), recruits Haspin to the inner centromere. Haspin phosphorylation by Aurora B (CPC), Cdk1, and PIk1 releases HBIS dependent Haspin auto-inhibition. Phosphatase activity toward H3T3ph by PP1Y-Repo-Man is inhibited through phosphorylation of Repo-Man by the CPC, which prevents Repo-Man recruitment to chromatin. (C) At the chromosome arms, Haspin levels are lower, most likely due to reduced levels of cohesin and SUMOylated Topoll. Low levels of chromatin targeted PP1Y-Repo-Man are sufficient to maintain H3T3 in a dephosphorylated state. (D) Upon anaphase onset, loss of Cdk1 activity promotes the PP1Y-Repo-Man interaction, resulting in high levels of the active complex associated with chromatin.

data suggest that while Pds5B may bind to the cohesin complex to concentrate Pds5B at centromeres, its association with chromatin does not depend on this interaction per se. Intriguingly, Pds5B has been shown to directly bind to DNA via two C-terminal AT hook domains (absent in Pds5A) (Couturier et al., 2016). How these domains contribute to localization of Pds5B and 


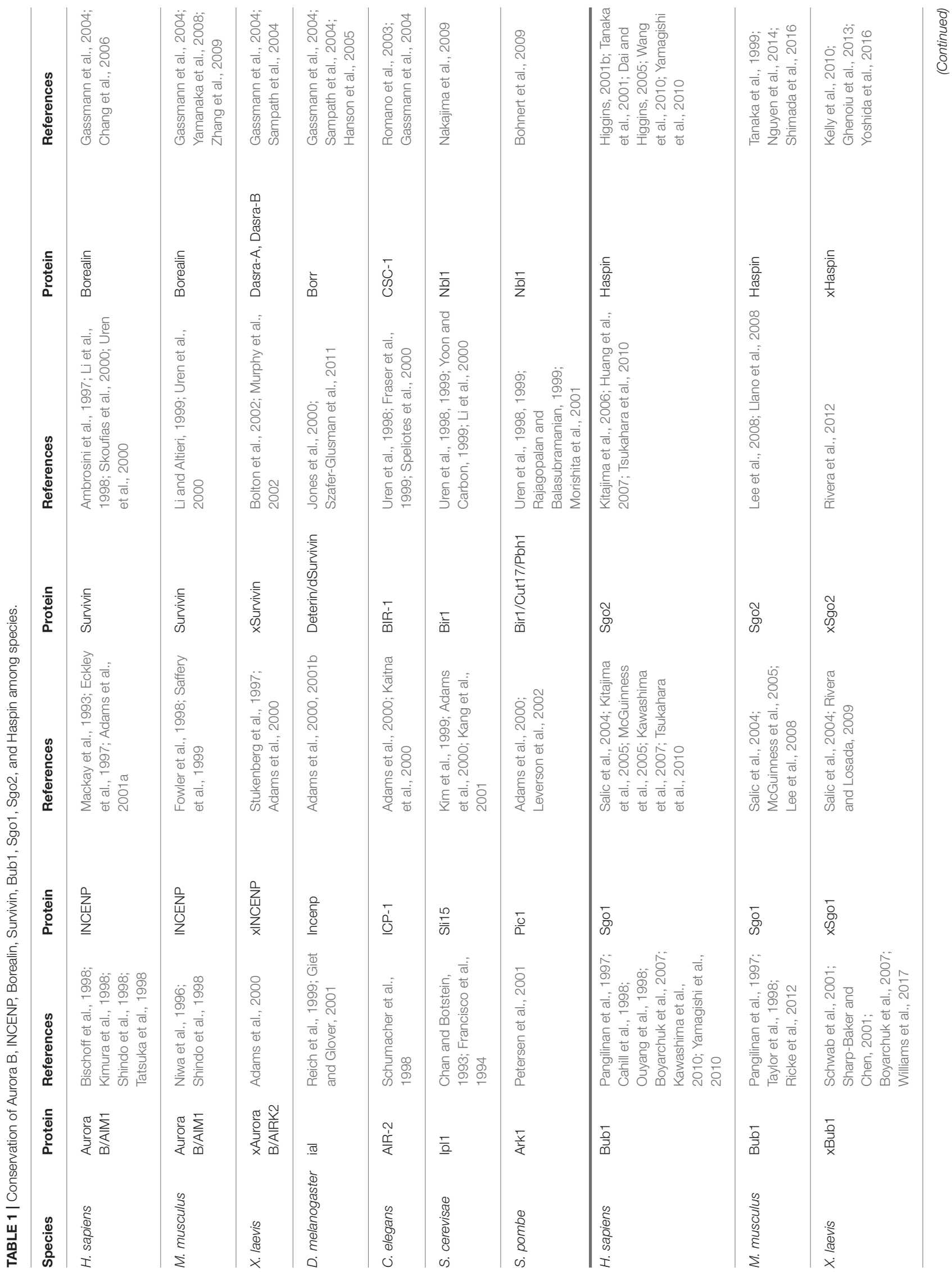


Hindriksen et al.

Aurora B Inner Centromere Localization

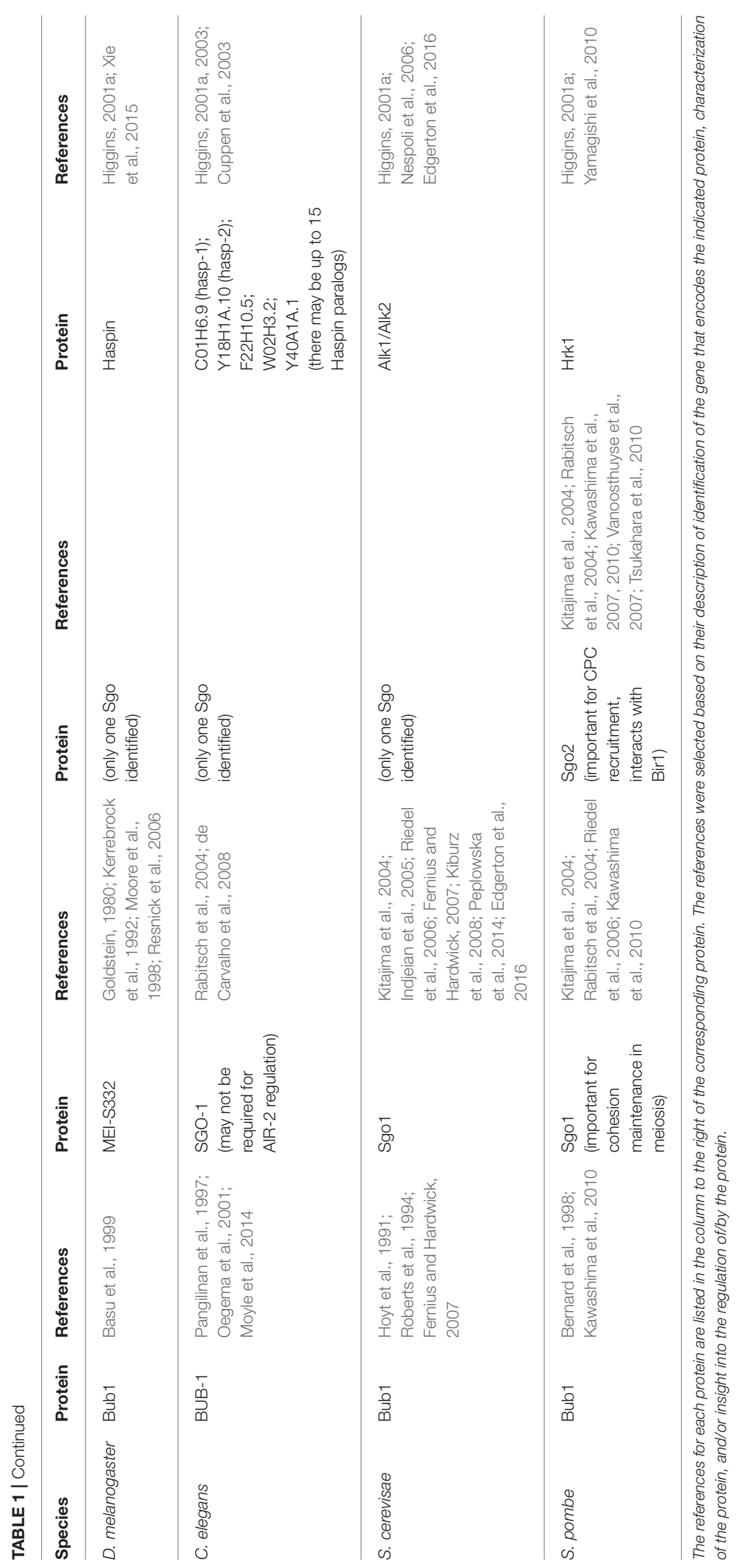

Frontiers in Cell and Developmental Biology | www.frontiersin.org

December 2017 | Volume 5 | Article 112 
Haspin during interphase and mitosis will require further investigation.

\section{Regulation of Haspin Activity}

Apart from its localization, Haspin activity itself is subject to further regulation, adding an extra layer of complexity. Haspin is an atypical kinase and its activity is not controlled by phosphorylation of the activation loop (Eswaran et al., 2009; Villa et al., 2009). Instead, the unstructured $\mathrm{N}$-terminal part of the protein harbors a unique autoinhibitory motif termed the Haspin Basic Inhibitory Segment or HBIS (Ghenoiu et al., 2013; Zhou et al., 2014). During mitosis, Cdk1, Plk1, and Aurora $\mathrm{B}$ phosphorylate multiple residues in the $\mathrm{N}$-terminal region of Haspin, thereby releasing the HBIS and thus resulting in full Haspin activity (Wang et al., 2011; Ghenoiu et al., 2013; Zhou et al., 2014). This highlights a key positive feedback loop through which Aurora B activity contributes to its own localization.

Despite the presence of the HBIS sequence, recombinant Haspin isolated from E. coli or from interphase cell extracts displayed robust activity toward H3 in vitro (Dai et al., 2005; Ghenoiu et al., 2013). Furthermore, a Haspin mutant isolated from mitotic cells, but lacking 11 putative Aurora B consensus sites, was still able to phosphorylate $\mathrm{H} 3$ in vitro, despite displaying a strong decrease in H3T3 phosphorylation in cells (Wang et al., 2011). While a more detailed analysis has shown that phosphorylation by Plk1 modestly stimulates the kinetics of H3T3 phosphorylation by Haspin (Ghenoiu et al., 2013) the discrepancy between in vitro and in vivo kinase activity of Haspin mutants suggest that in cells the substrate H3T3 is regulated by additional factors.

\section{Regulation of H3T3 Phosphorylation}

H3T3 phosphorylation is reversed by PP $1 \gamma$. The activity of PP1 typically relies on the association with a regulatory factor that controls its targeting to its substrates. Activity toward H3T3ph requires the PP $1 \gamma$-interacting protein Repo-Man, which recruits PP1 $\gamma$ to chromatin. Together they control H3T3ph levels through an intricate circuit that further depends on the activity of Cdk1 and Aurora B (Trinkle-Mulcahy et al., 2006; Qian et al., 2011; Vagnarelli et al., 2011). During mitosis, Cdk1-mediated phosphorylation of Repo-Man largely represses its interaction with PP1 $\gamma$ and chromatin (Figures 3B,C). However, low levels of chromatin bound PP1 $\gamma$-Repo-Man appear sufficient for removal of H3T3ph on the chromosome arms, while other mitotic substrates remain below the threshold for dephosphorylation. Centromeric H3T3ph is protected from PP1 $\gamma$-Repo-Man activity by Aurora B, which phosphorylates Repo-Man on serine 893 (S893). This results in a strong decrease in affinity for histones, thus effectively reducing PP1 $\gamma$ activity at centromeres (Qian et al., 2013). On the other hand, Cdk1 activity promotes the interaction between Repo-Man and PP2A, which can dephosphorylate Repo-Man S893, thereby controlling basal chromatin levels of PP $1 \gamma$-Repo-Man during mitosis (Qian et al., 2015). This feedback between PP1 $\gamma /$ PP2A/Repo-Man and Cdk1 and Aurora $\mathrm{B}$ contributes to restricting $\mathrm{H} 3 \mathrm{~T} 3 \mathrm{ph}$, and thus the $\mathrm{CPC}$, to centromeres. Furthermore, it facilitates the switch-like behavior observed at mitotic exit: the drop in Cdk1 activity upon anaphase onset results in full activity of PP $1 \gamma$-Repo-Man on chromatin, thereby allowing rapid and complete dephosphorylation of mitotic substrates (Figure 3D).

\section{Regulation of Haspin at the Substrate Level: Epigenetic Context}

Survivin is a "reader" of H3T3ph (Kelly et al., 2010; Wang et al., 2010). However, Histone H3 tails are subject to many more posttranslational modifications and their juxtaposition to H3T3 makes it tempting to speculate they could contribute to regulation of H3T3 accessibility to Haspin or to Survivin binding. In fact, crosstalk between multiple histone marks is commonly observed as a means for reversibly controlling chromatin association of proteins. For example, heterochromatin protein 1 (HP1) specifically interacts with $\mathrm{H} 3$ when lysine 9 is trimethylated. However, phosphorylation of $\mathrm{H} 3 \mathrm{~S} 10$ by Aurora B results in eviction of HP1, thereby creating a so-called "methyl/phosphor" switch (Fischle et al., 2005; Hirota et al., 2005). In case of H3T3, methylation of the adjacent residues H3R2 and H3K4 has been shown to negatively influence Haspin activity toward H3T3 in vitro (Figures 4A,D) (Eswaran et al., 2009; Villa et al., 2009; Han et al., 2011; Karimi-Ashtiyani and Houben, 2013).

This raises several questions: Do these marks occur during mitosis and if so, where? Several observations suggest this could be the case. First, despite the fact that $\mathrm{H}_{3} \mathrm{~K}_{4} \mathrm{Me}_{3}$ suppresses $\mathrm{H} 3 \mathrm{~T} 3$ phosphorylation by Haspin in vitro, it has been observed in mitotic cells in a combinatorial mark together with H3T3ph and H3R8Me 2 (Markaki et al., 2009). Moreover, this mark was highly enriched at centromeres. Unfortunately, the functional significance of this modification remains unresolved. Intriguingly, $\mathrm{H} 3 \mathrm{~T} 3 \mathrm{ph}$ has been shown to decrease the binding of the transcription factor complex TFIID to $\mathrm{H} 3 \mathrm{~K}_{4} \mathrm{Me}_{3}$, suggesting the presence of a "methyl/phosphor" switch that represses transcription during mitosis (Varier et al., 2010). At the same time, $\mathrm{H} 3 \mathrm{~K}_{4} \mathrm{Me}_{2}$ dependent transcription at centromeres does occur and has been shown to play an important role in regulating centromere function, including the regulation of Aurora B activity (Figure 4C) (Sullivan and Karpen, 2004; Jambhekar et al., 2014; Blower, 2016; Molina et al., 2016; McNulty et al., 2017). This in turn raises the question if Haspin contributes to the regulation of centromeric transcription. Perhaps the confinement of Haspin and H3T3ph to the inner centromere restricts transcriptional start sites to kinetochore-proximal centromeres, suggesting the presence of multiple functional domains within centromeres (Sullivan and Karpen, 2004). If and how Haspin controls centromeric transcription will require further analysis.

Of note, while modification of residues adjacent to H3T3 clearly influences H3T3 phosphorylation, it remains unclear how modifications in the vicinity of H3T3ph would influence binding to Survivin. Analysis of the structure of a complex between Survivin and a $\mathrm{H} 3$ peptide reveals extensive interactions between H3R2 and H3K4 with the BIR domain of Survivin (Figures 4B,E) (Jeyaprakash et al., 2007; Kelly et al., 2010; Niedzialkowska et al., 2012). However, while both H3R2 and 


\section{$\&$ cen-RNA (me2) dimethylation \\ (2) phosphate group (me3) trimethylation}
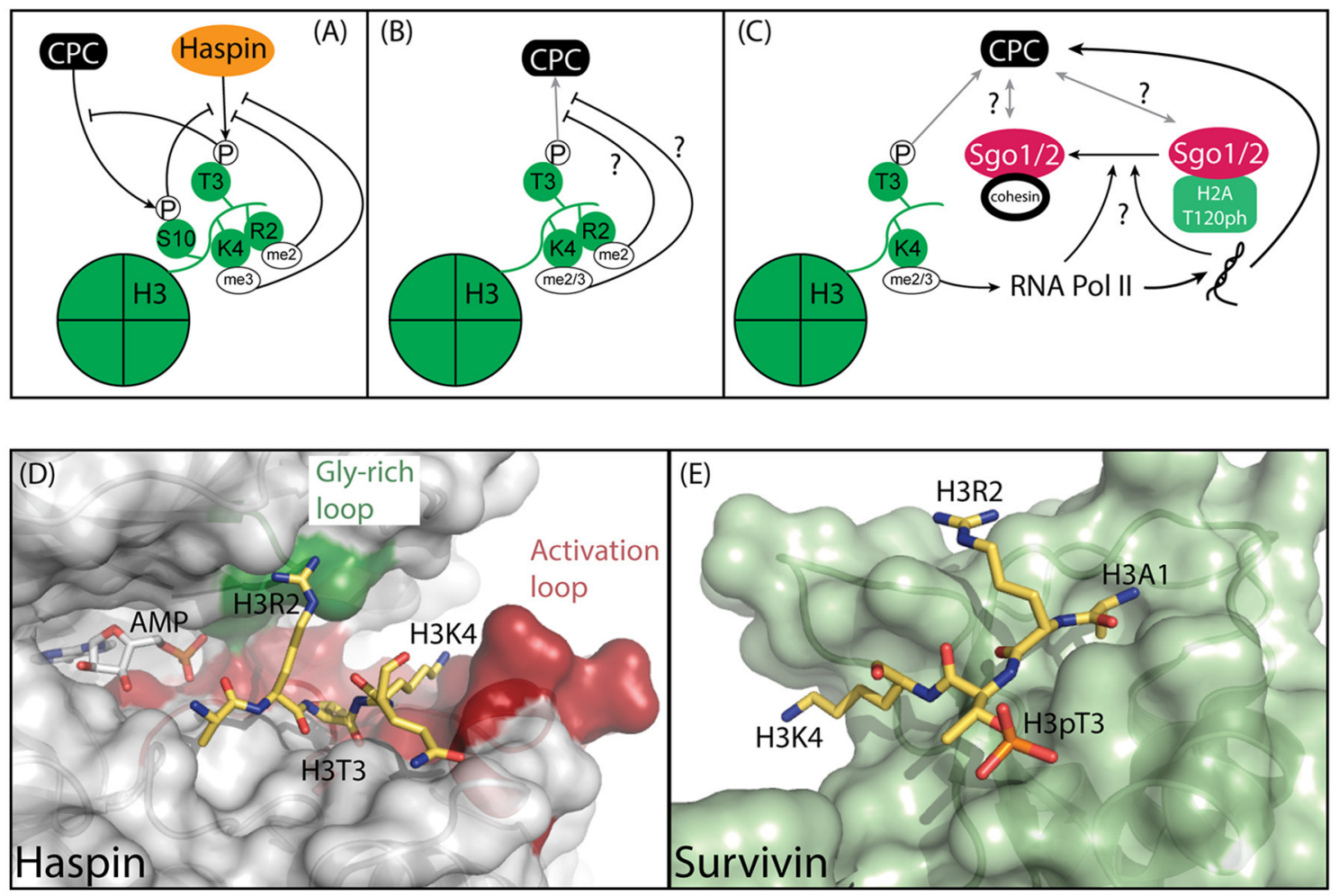

FIGURE 4 | Model of how the epigenetic context of H3T3 might influence its phosphorylation by Haspin and its capacity to recruit the CPC. (A) Methylation and phosphorylation of the histone tail of H3 impede H3T3 phosphorylation. H3T3ph impedes phosphorylation of H3S10. (B) Methylation of residues adjacent to H3T3ph could hinder the interaction of H3T3ph with Survivin, thereby impeding CPC recruitment. (C) H3K4 di/trimethylation is associated with centromere transcription, which is required for full Aurora B activity and CPC localization to the inner centromere. Centromeric transcription and/or the resulting transcript also regulate(s) Sgo $1 / 2$ translocation from the kinetochore-proximal centromere to the inner centromere, however it is unclear if this is related to the effect of transcription on the CPC. (D) Close-up of the active site of Haspin (gray) bound to its substrate, Histone H3 (yellow) (PDB ID: 2WB8). The AMP moiety is modeled based on PDB ID 3DLZ. The structure reveals extensive interaction between $\mathrm{H} 3 \mathrm{R} 2$ and the Gly-rich loop, depicted in green, and H3K4 and the activation loop, depicted in red. As such, modifications of residues adjacent to H3T3 could influence substrate binding. (E) Close-up of Survivin (light green), bound to a Histone H3 peptide (yellow) (PDB ID: $3 \mathrm{UIG}$. The structure depicts the interactions between $\mathrm{H} 3$ and the BIR domain of Survivin.

H3K4 make multiple electrostatic interactions with Survivin these side chains adopt an extended conformation over the surface of Survivin, suggesting ample space to accommodate additional modifications (Figures 4B,E). Ultimately, if and how H3 modification beyond H3T3 phosphorylation affect Survivin binding beyond H3T3 phosphorylation will need to be addressed experimentally.

Interestingly, H3S10 phosphorylation by Aurora B was shown to significantly impede $\mathrm{H} 3 \mathrm{~T} 3$ phosphorylation in vitro and vice versa, suggesting that these "common" mitotic histone marks may not coexist on the same histone tail (Han et al., 2011). This type of crosstalk again suggests the possible presence of multiple domains, each carrying unique combinatorial marks within the $3 \mathrm{D}$ organization of centromeres. The presence of such domains and how they may contribute to CPC localization and chromosome segregation during mitosis remain unclear and will require further analysis.

\section{Bub1, H2AT120ph and the Inter-kinetochore Axis}

Haspin activity controls CPC localization to the inter-sister chromatid region by virtue of its association with cohesin (Figures 1, 2, 3B). On the other hand, Bub1 kinase activity concentrates the inter-sister pool of the CPC at centromeres. Bub1 is thought to exert its control over CPC localization through recruitment of Sgo1 and Sgo2 but how Bub1 and Sgo1/2 collaborate to control CPC localization remains poorly understood at the molecular level.

Bub1 is recruited to chromatin via its association with the kinetochore protein Knl1 (Figure 5). Importantly, this restricts Bub1 activity to the centromere region (Figures 1,2) (Kiyomitsu et al., 2007, 2011). Knl1 forms an important signaling platform within the KMN network and its location at the microtubulekinetochore interface allows it to control mitotic checkpoint signaling and chromosome congression (Caldas and DeLuca, 2014). Bubl is recruited to Knll as part of a larger complex that 


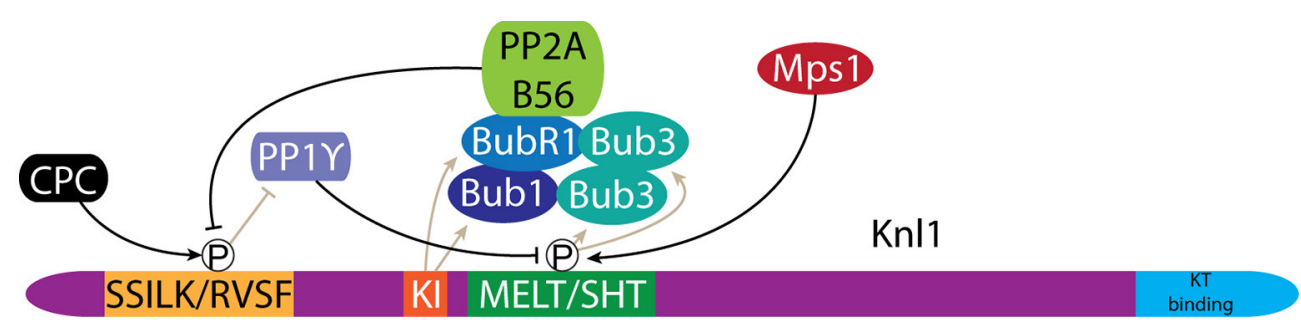

FIGURE 5 | Bub1 recruitment to kinetochores is regulated by phosphorylation of Knl1. Phosphorylation of MELT/SHT motifs in Knl1 by Mps1 mediates recruitment of the Bub proteins. A negative feedback loop is created through the recruitment of PP2A/B56, which antagonizes phosphorylation of the SSILK/RVSF motifs by the CPC. Dephosphorylation of the SSILK/RVSF motifs allows PP1 $\gamma$ binding, which in turn antagonizes MELT/SHT phosphorylation.

further consists of Bub3 and BubR1 (collectively referred to as the Bubs) (Taylor et al., 1998). Recruitment of the Bubs depends on the activity of the mitotic kinase Mps1, which phosphorylates an array of so-called MELT/SHT motifs in Knl1 (London et al., 2012; Shepperd et al., 2012; Yamagishi et al., 2012; Primorac et al., 2013; Vleugel et al., 2013, 2015). Bub3 specifically recognizes these motifs, resulting in recruitment of the Bubs to the kinetochore (London et al., 2012; Shepperd et al., 2012; Yamagishi et al., 2012; Primorac et al., 2013; Vleugel et al., 2013, 2015). The recruitment of the Bubs is further enhanced through a direct interaction between the TPR domains of Bub1 and BubR1 and two "KI" motifs in Knl1 (Bolanos-Garcia et al., 2011; Kiyomitsu et al., 2011; Krenn et al., 2012).

The level of Bub1 at kinetochores is tightly controlled through an intricate regulatory circuit that couples the microtubule attachment status of the kinetochore to Bub1 levels. Bub1 levels are higher at unattached vs. microtubule attached kinetochores (Jablonski et al., 1998; Hoffman et al., 2001; Skoufias et al., 2001; Taylor et al., 2001; Ditchfield et al., 2003), but also appears higher at attached kinetochores with reduced tension across centromeres (Skoufias et al., 2001; Taylor et al., 2001). PP1 $\gamma$ activity antagonizes Mps1 dependent recruitment of the Bubs (Figure 5). Knl1 directly recruits PP1 $\gamma$ to kinetochores where it binds to a conserved SSILK/RVSF motif. PP1 $\gamma$ levels are in turn controlled by the activities of Aurora B and PP2A. Aurora B directly phosphorylates the Knl1 SSILK/RVSF motif, which inhibits PP1 $\gamma$ binding while PP2A antagonizes Aurora B phosphorylation, thereby promoting PP1 $\gamma$ binding to Knl1 (Figure 5) (Liu et al., 2010; Nijenhuis et al., 2014). Interestingly, it is BubR1 that recruits PP2A to kinetochores (Suijkerbuijk et al., 2012; Kruse et al., 2013; Xu et al., 2013). As such, the association of the Bubs with Knll at the same time primes their removal. This negative feedback ensures a responsive mitotic checkpoint signal but likely also contributes to controlling CPC levels at centromeres (Nijenhuis et al., 2014). Indeed, both Sgol and Aurora B levels are higher at unattached kinetochores (Salimian et al., 2011; Liu et al., 2013a; Meppelink et al., 2015). This is in line with the role of Aurora B in establishing bi-orientation. Early in mitosis high Aurora B activity is required to destabilize potential erroneous kinetochore-microtubule (KT-MT) interactions, while Aurora B activity must later be down-regulated to support formation of stable bi-oriented KT-MT interactions (see discussion below) (Salimian et al., 2011; Krenn and Musacchio, 2015).

\section{The Role of Sgo1 in CPC Localization}

Bub1-mediated phosphorylation of H2AT120 directly recruits Sgo1 and Sgo2 to centromeres (Tang et al., 2004; Kitajima et al., 2005; Gómez et al., 2007; Kawashima et al., 2010; Tanno et al., 2010; Liu et al., 2013b). How then does this contribute to the (inner) centromere localization of the CPC? First, by recruiting Sgo1/2 to centromeres Bub1 ensures centromeres are protected from the cohesin removing activity of the prophase pathway (McGuinness et al., 2005; Kitajima et al., 2006; Kawashima et al., 2010; Tanno et al., 2010), which likely contributes to restricting cohesin associated Haspin to centromeres (see above). Depletion or inhibition of Bub1 results in so-called closed arm chromosomes, as the prophase pathway no longer removes cohesin from the chromosome arms. This effect depends on Sgol (Kitajima et al., 2005), which, along with Haspin and the CPC, is redistributed along the inter-sister chromatid axis (Ricke et al., 2012; Liu et al., 2013a; Baron et al., 2016).

The data so far suggest that the Bub1 $>$ H2AT120ph $>$ Sgol/2 pathway might simply act as a roadblock against cohesin removal, and thereby Haspin removal, from centromeres. As such this pathway would indirectly contribute to the enrichment of $\mathrm{H} 3 \mathrm{~T} 3 \mathrm{ph}$ at the inner centromere. Yet, yeast-2-hybrid experiments suggest that Sgo1/2 directly interact with Borealin (Tsukahara et al., 2010; Lee et al., 2014). This implies that Sgo1/2 also play a direct role in CPC centromere localization, but the exact mechanism remains poorly understood. In fission yeast, Sgo2 is the main contributor to CPC localization during mitosis, and while Sgo2 has been shown to contribute to CPC localization in human cells its role remains understudied (Table 1) (Yamagishi et al., 2010). We will therefore limit our discussion to the role of Sgo1.

Recruitment of Sgol to the inner centromere is a two-step process. First, Sgol is recruited to H2AT120ph, located at two centromeric foci, proximal to the kinetochores (Figure 2) (Lee et al., 2008; Liu et al., 2013a, 2015). Then, in a second step, Sgo1 moves to the inner centromere by binding to the cohesin complex (Liu et al., 2013a). Sgol binds cohesin at the interface between the SA2 and Scc1 subunits and this interaction further requires phosphorylation of Sgo1T346 by Cdk1 (Liu et al., 2013b; Hara et al., 2014). Sgol mutants that are unable to bind to H2AT120ph 
no longer accumulate at the (inner) centromere, while mutations that prevent binding to cohesin result in accumulation of Sgol at the centromere pools of H2AT120ph, proximal to the kinetochores (McGuinness et al., 2005; Kawashima et al., 2010; Liu et al., 2013a,b, 2015). This suggests that the association of Sgo1 with H2AT120ph forms a crucial intermediate step prior to translocating to the inner centromere (Liu et al., 2015). Interestingly, Bub1 activity at kinetochores also contributes to the localization of actively transcribing RNA polymerase II (Pol II) (Chan et al., 2012; Liu et al., 2015). Moreover, Bub1-dependent transcription at centromeres is required for translocation of Sgol to the inner centromere. Sgol was shown to bind to RNA and Pol II, but how centromeric transcription results in inner centromere localization remains unclear (Liu et al., 2015). Centromeric transcription has been shown to generate multiple species of lncRNAs that play important roles in kinetochore assembly and regulation of CPC activity (Sullivan and Karpen, 2004; Jambhekar et al., 2014; Blower, 2016; McNulty et al., 2017). Importantly, since Aurora B activity also contributes to Sgo1 localization these studies should be interpreted cautiously as indirect effects of centromeric RNA on Sgo1 localization via Aurora B cannot be excluded (van der Waal et al., 2012; Lee et al., 2014).

How then does Sgol contribute to CPC localization? Sgol has been shown to interact with the CPC, specifically with Borealin in a Cdk1 dependent fashion (Kawashima et al., 2007; Tsukahara et al., 2010; Jeyaprakash et al., 2011; Liu et al., 2015). This makes it tempting to speculate that the CPC tags along with Sgol toward the inner centromere. First, Sgol would recruit the CPC toward H2AT120ph at the kinetochore-proximal centromere. The subsequent association of Sgol with cohesin may drag the CPC toward the inner centromere, aided by the interaction between Survivin and H3T3ph (Figure 2). However, this model raises several questions: if the CPC and Sgol translocate to the inner centromere as a single unit then $\mathrm{H} 3 \mathrm{~T} 3 \mathrm{ph}$ would also be expected to contribute to inner centromere localization of Sgo1. Indeed, knockout (KO) of Haspin in human cells was shown to result in redistribution of Sgol from the inner centromere toward the two kinetochore-proximal pools of H2AT120ph (Zhou et al., 2017). However, these results must be interpreted cautiously since Haspin was also shown to directly contribute to protection of centromeric cohesion (Dai et al., 2006; Zhou et al., 2017). In fact, depletion of Wapl from Haspin KO cells was sufficient to restore inner centromere localization of Sgo1, suggesting that $\mathrm{H} 3 \mathrm{~T} 3 \mathrm{ph}$ is not required for inner centromere localization of Sgo1. Since the localization of the CPC was not addressed in these studies (Zhou et al., 2017), it remains to be seen if depletion of Wapl in Haspin KO cells is able to rescue inner centromere localization of the CPC.

Other observations argue against the "tag along" model. First, mouse embryonic fibroblasts engineered to express kinase dead Bub1 where shown to have closed arms with Aurora B localized along the inter-sister chromatid axis (Ricke et al., 2012). This may imply that delocalized Sgo1, caused by the lack of Bub1 activity, results in redistribution of the $\mathrm{CPC}$, along the lines of the "tag along" model. However, specific targeting of Sgo1 to centromeres, through ectopic expression of Sgol fused to the centromere-targeting domain of CENP-B, was unable to rescue (inner) centromere enrichment of the CPC (Ricke et al., 2012). Furthermore, while depletion of Sgol reduces centromere levels of the CPC, overexpression of Sgo1 does not result in a concomitant increase of the CPC (Meppelink et al., 2015). This is in contrast to PP2A, which binds directly to an $\mathrm{N}$-terminal coiled coil in Sgo1, and whose levels at the inner centromere strongly correlate with Sgo1 (Meppelink et al., 2015). This suggests that while Sgol contributes to CPC localization at centromeres, the inner centromere pool of Sgol may not be associated with the CPC. Of note, mapping of the Borealin binding site in Sgol has pinpointed the N-terminal coiled coil that also binds $\mathrm{PP} 2 \mathrm{~A}$, raising the question if the interaction between Sgo1-PP2A and Sgo1-CPC are perhaps mutually exclusive (Xu et al., 2009; Tsukahara et al., 2010). For now, the interaction between the CPC and Sgol remains poorly characterized. Future analysis should allow for the identification of Sgol mutants that specifically disrupt its interaction with the CPC, to shed light on the molecular basis of how Sgol contributes to the localization of the CPC.

\section{Aurora B-Mediated Control of CPC Localization}

It is clear that complex signaling underlies the defined localization of the CPC at the inner centromere. It is intriguing that almost every pathway that contributes to confining the $\mathrm{CPC}$ to the inner centromere is under control of Aurora B activity itself. This includes the important roles of Aurora B in the prophase pathway, in the maintenance of centromeric cohesion, in Haspin activation, in the control of H3T3ph levels and in the regulation of Bub1 and Sgol levels at the kinetochore and (inner) centromere, respectively. Furthermore, Aurora B phosphorylation of H2AXS121 at centromeres has been shown to contribute to (inner) centromere localization of the CPC (Shimada et al., 2016). As these various pathways converge to concentrate the CPC at the inner centromere they further contribute to the positive feedback cycle as clustering has been shown to contribute to full activation of Aurora B by facilitating the auto-phosphorylation, in trans, of its activation loop (Bishop and Schumacher, 2002; Kelly et al., 2007).

At the same time these data highlight an important challenge in studying the localization of the CPC. Extensive crosstalk between cohesin, Haspin, Bub1, Sgo1, and the CPC make it difficult to explain at the molecular level the phenotypic observations following perturbation of the system. Loss of Sgol and Haspin both result in a loss of (centromere) cohesion and thus in essence in the absence of an inner centromere. The identification of separation of function alleles that uncouple the multiple functions of these proteins will be required to further unravel the underlying signaling that controls CPC localization.

\section{IS INNER CENTROMERE LOCALIZATION OF THE CPC REQUIRED FOR CPC FUNCTION DURING MITOSIS?}

As explained above, an intricate and evolutionary conserved signaling network that is operational in our cells directs the 
CPC toward the inner centromere region of the duplicated chromosomes. This typical localization of the CPC has for long been considered crucial for the various mitotic functions executed by its enzymatic subunit Aurora B. However, several recent pieces of data challenge this view. Below we will summarize the contribution of the CPC to error-free chromosome segregation and discuss the various lines of evidence that argue for or against the need for precise localization of the CPC at the inner centromere for its activities contributing to faithful chromosome segregation.

\section{The CPC Is Essential to Achieve Chromosome Bi-Orientation}

Error-free chromosome segregation requires that all the duplicated chromosomes become bi-oriented on the mitotic spindle. This means that the kinetochores of the sister chromatids need to become attached to microtubules derived from opposite poles of the mitotic spindle prior to anaphase onset. Through phosphorylation of outer kinetochore proteins that directly bind to spindle microtubules, such as components of the KMN network (particularly $\mathrm{Ndc} 80 / \mathrm{Hec} 1$ ), Aurora B lowers their microtubule binding affinity and as such creates a dynamic KTMT interface where individual microtubules continuously bind the kinetochore and are rapidly released. This high kinetochore microtubule (kMT) turnover helps to resolve "unwanted" nonbipolar KT-MT interactions, such as syntelic (sister-kinetochores are bound by microtubules from the same pole) and merotelic (one of the sister kinetochores is bound by microtubules from opposite spindle poles) attachments, that would otherwise give rise to mis-segregating chromosomes in anaphase, resulting in aneuploid daughter cells (Thompson et al., 2010). This process is frequently referred to as "error correction." A consequence of kMT detachment is an unattached kinetochore that activates the mitotic checkpoint, a surveillance mechanism that prevents the onset of anaphase until all kinetochores have become stably connected to microtubules of the mitotic spindle (Musacchio, 2015). Aurora B also contributes to the mitotic checkpoint in a more direct manner by facilitating the rapid kinetochore recruitment of the essential checkpoint kinase Mps1 at the onset of mitosis (Santaguida et al., 2011; Saurin et al., 2011). This dual activity of Aurora B ensures that bi-oriented attachments can be established before anaphase onset. Obviously, kMT turnover needs to eventually diminish to allow the stabilization of bioriented attachments and silencing of the mitotic checkpoint. The switch from dynamic to more stable kMT interactions on bi-oriented chromosomes is accompanied by tension across and within the sister-kinetochores (Nicklas and Koch, 1969; Ault and Nicklas, 1989; Maresca and Salmon, 2009; Uchida et al., 2009). Tension is generated by opposing microtubule pulling forces that are counteracted by centromeric cohesin, which holds the sister chromatids together, as well as by the inner kinetochore proteins CENP-T, CENP-H/I/K/M, and CENP-C, which act as linkers between the core centromere protein CENP-A and the microtubule binding site of the kinetochore Ndc80/Hec1 (Nicklas and Koch, 1969; Ault and Nicklas, 1989; Suzuki et al., 2014; Musacchio and Desai, 2017). At least in vitro, tension itself stabilizes KT-MT attachments through a catch-bond like mechanism (Akiyoshi et al., 2010). Yet, tension also increases the distance between the sister-kinetochores, as well as between the inner centromere where Aurora B is localized, and the outer kinetochore where its MT binding substrates reside (Wan et al., 2009). This gave rise to the "spatial separation model," which explains the stability of KT-MT attachments by the proximity of Aurora B to its kinetochore substrates: mal-attachments are destabilized because Aurora B can reach its outer kinetochore substrates and phosphorylate them, while bi-oriented (amphitelic) attachments are stabilized because the opposing microtubules pulling forces generated on bi-oriented chromosomes pull the outer kinetochore substrates out of the sphere of influence of Aurora B (Tanaka et al., 2002; Andrews et al., 2004; Liu et al., 2009). Indeed, a FRETbased biosensor for Aurora B activity is phosphorylated on bi-oriented sister chromatids when placed at the centromere, but not when it is positioned at the kinetochore (Liu et al., 2009). Similarly, the level of phosphorylation of endogenous Aurora B kinetochore substrates, such as Hec1, goes down upon microtubule attachment and the generation of tension across kinetochores (Welburn et al., 2010; DeLuca et al., 2011), while hyperstretching of the kinetochore, which occurs in cells lacking CENP-T or CENP-C, causes an even greater reduction in $\mathrm{Hec1}$ phosphorylation (Suzuki et al., 2014). These data seem to be in line with the view that the distance between Aurora B and its substrate contributes to the level of phosphorylation of that substrate after bi-orientation. This is further substantiated by the observation that the central region of INCENP is a $\sim 32 \mathrm{~nm}$ single alpha helix (SAH) that might stretch up to $80 \mathrm{~nm}$ under physiological forces (Peckham and Knight, 2009; Samejima et al., 2015). This extensible SAH connects the $\mathrm{N}$-terminal centromere binding domain of INCENP with its C-terminal Aurora B binding domain, and may act as a "dog-leash" allowing Aurora $\mathrm{B}$ to phosphorylate its outer kinetochore substrates, while being tethered to the inner centromere (Santaguida and Musacchio, 2009; Samejima et al., 2015). In line with this idea, deletion of the SAH affected Aurora B-mediated phosphorylation of outer kinetochore substrates but not of inner centromere-proximal substrates (Samejima et al., 2015; Wheelock et al., 2017).

A key condition for this tension-based spatial separation model is the confined localization of Aurora B at the inner centromere. The model predicts that placement of Aurora B closer to the outer kinetochore would preclude stabilization of bi-oriented kMTs. By replacing the N-terminal (Survivin and Borealin binding) inner centromere-targeting domain of INCENP with the centromere-binding domain of CENP-B (CB-INCENP) or with the kinetochore protein Mis12 (Mis12INCENP), it is possible to target Aurora B close to or at the kinetochore, respectively (Liu et al., 2009). In both cases, chromosomes initially bi-orient but are not retained in the metaphase plate. This phenotype was interpreted as ongoing destabilization of amphitelically attached kMTs by kinetochoreproximal Aurora B (Liu et al., 2009). However, it was recently shown that the microtubule binding protein $\mathrm{Hecl}$ can be dephosphorylated and bi-oriented attachments can be stabilized in cells with kinetochore-proximal Aurora B if cohesin removal 
is prevented via depletion of Wapl (Hengeveld et al., 2017). The absence of the CEN module of the CPC, comprising the INCENP N-terminus, Survivin and Borealin, appeared to weaken centromere cohesion and to accelerate cohesion fatigue, causing sister chromatids to separate before anaphase (Daum et al., 2011; Hengeveld et al., 2017). These data suggested that inner centromere localization of Aurora B is not a prerequisite for the destabilization of erroneous KT-MT attachments nor for the stabilization of correct KT-MT attachments, in line with earlier observations in budding yeast. Here, deletion of the centromeretargeting domain of the INCENP homolog Sli15 causes the CPC to localize to the mitotic spindle and to kinetochores, instead of to the inner centromere. Even though this alternative localization would preclude spatial separation between the CPC and kinetochores upon bi-orientation, these cells did not show severe defects in chromosome segregation, suggesting that stable kMT interactions could be formed (Campbell and Desai, 2013). Of note, the relocation of Aurora $\mathrm{B}$ to the spindle and to kinetochores by expression of an INCENP mutant lacking its centromere-targeting domain (referred to as dCEN-INCENP) is not observed in human cells or Xenopus laevis egg extracts supplemented with sperm chromatin. This probably explains why dCEN-INCENP fails to rescue any Aurora B function in these experimental systems: it is most likely insufficiently clustered to activate Aurora B (Vader et al., 2006; Kelly et al., 2007; Haase et al., 2017; Hengeveld et al., 2017).

\section{CPC Inner Centromere Localization, What Is It Good For?}

Based on the above, one could argue that the main function of CPC (inner) centromere localization is to cluster and activate Aurora B. If so, then all mitotic functions of the CPC should be restored when INCENP and Aurora B are clustered in an alternative manner or at an alternative location. This may be true for budding yeast, but it does not seem to be the case in other systems. In X. laevis egg extracts, antibody-mediated clustering of dCEN-INCENP activates Aurora B outside the chromatin. Interestingly, this unfocussed, or global Aurora B activity is sufficient to rescue outer kinetochore assembly in CPC depleted extracts, but does not support full chromosome bi-orientation (Figure 6). Interestingly, Hec1 is phosphorylated but the levels of phosphorylation are reduced on unattached kinetochores compared to wild-type (WT)-CPC extracts and remain constant after bi-orientation. Consequently, in metaphase the levels of Hecl phosphorylation are higher in the dCEN-INCENP clustered extracts compared to WT-CPC extracts (Haase et al., 2017). Therefore, it remains unclear if the defective bi-orientation in the dCEN-INCENP clustered extracts is due to a failure in destabilizing erroneous attachments during (pro)metaphase or a failure in stabilizing bi-oriented attachments in metaphase. Addition of the CEN module to extracts with unfocussed Aurora $\mathrm{B}$ activity did not restore $\mathrm{Hec} 1$ phosphoregulation, suggesting that centromere or at least chromatin-localized Aurora B is required for $\mathrm{Hecl}$ phosphoregulation in response to attachments and tension (Haase et al., 2017). As mentioned, CEN module independent clustering of Aurora B near or at kinetochores in human cells, via expression of CB-INCENP or Mis12INCENP respectively, does not preclude the dephosphorylation of Hecl and the formation of stabile amphitelic attachments if cohesion is stabilized (Figure 6) (Hengeveld et al., 2017). This seems to support the $X$. laevis data, suggesting that attachment and tension-dependent $\mathrm{Hecl}$ phosphoregulation requires chromosome-associated Aurora B activity, but not precise inner centromere Aurora B localization. While stable amphitelic attachments can be formed in cells with kinetochoreproximal Aurora $\mathrm{B}$, these cells do experience a substantial delay in metaphase because they fail to silence the mitotic checkpoint (Figure 6) (Hengeveld et al., 2017). In contrast to Hecl, the kinetochore protein Knl1 remained phosphorylated by Aurora $B$, thereby preventing the recruitment of PP1 $\gamma$ to Knll, which is required for silencing of the mitotic checkpoint (Caldas and DeLuca, 2014; Nijenhuis et al., 2014; Hengeveld et al., 2017). It is appealing to conclude that checkpoint silencing requires the spatial separation of Aurora B and Knll and that this requires inner centromere localization of Aurora B. However, due to the nature of the experiments it cannot be excluded that mitotic checkpoint silencing somehow requires the removal of a potential kinetochore pool of Aurora B which is prevented in cells where Aurora $\mathrm{B}$ is constitutively placed near or at the kinetochore (DeLuca et al., 2011; Caldas et al., 2013).

An interesting picture emerging from these studies is that the CPC CEN module can fulfill certain CPC activities separately from the enzymatic Aurora B module, contrasting the idea that it is simply a targeting module for Aurora B (Figure 6). In human cells the CEN module strengthens centromeric cohesion to avoid premature sister chromatid separation after chromosome biorientation (Hengeveld et al., 2017). Moreover, in contrast to Aurora B kinase inhibition, depletion of both INCENP and Survivin from HeLa cells impairs inner kinetochore assembly; and in $X$. laevis egg extracts lacking the CPC, the CEN module suffices to rescue inner kinetochore assembly (Haase et al., 2017). It is currently unclear how the CEN module stabilizes centromeric cohesion and controls inner kinetochore assembly, but one can envision that these activities might require its presence at the inner centromere (Figure 6). In other words, maybe it is not Aurora $\mathrm{B}$ that needs to be at the inner centromere, but the CEN module of the CPC. If so, then perturbations that interfere with the accumulation of the $\mathrm{CPC}$ at the inner centromere would also affect the robustness of centromeric cohesion and/or inner kinetochore assembly. Although Haspin knockdown and KO cells experience cohesion fatigue due to weakened centromeric cohesin, this cannot be attributed solely to impaired CPC CEN module localization since Haspin itself directly controls centromeric cohesion by counteracting Wapl activity (Dai et al., 2005; Zhou et al., 2017). Evaluating centromeric cohesion and the inner kinetochore status in Survivin knockdown cells reconstituted with a Survivin BIR domain mutant that cannot bind H3T3ph (Lens et al., 2006; Yue et al., 2008; Wang et al., 2010), would be a more suitable way to test if the CEN module needs to be precisely positioned to execute these activities. Remarkably, cells expressing a Survivin BIR mutant, or with kinetochore-proximal Aurora B display a weakened mitotic checkpoint response when challenged with the 


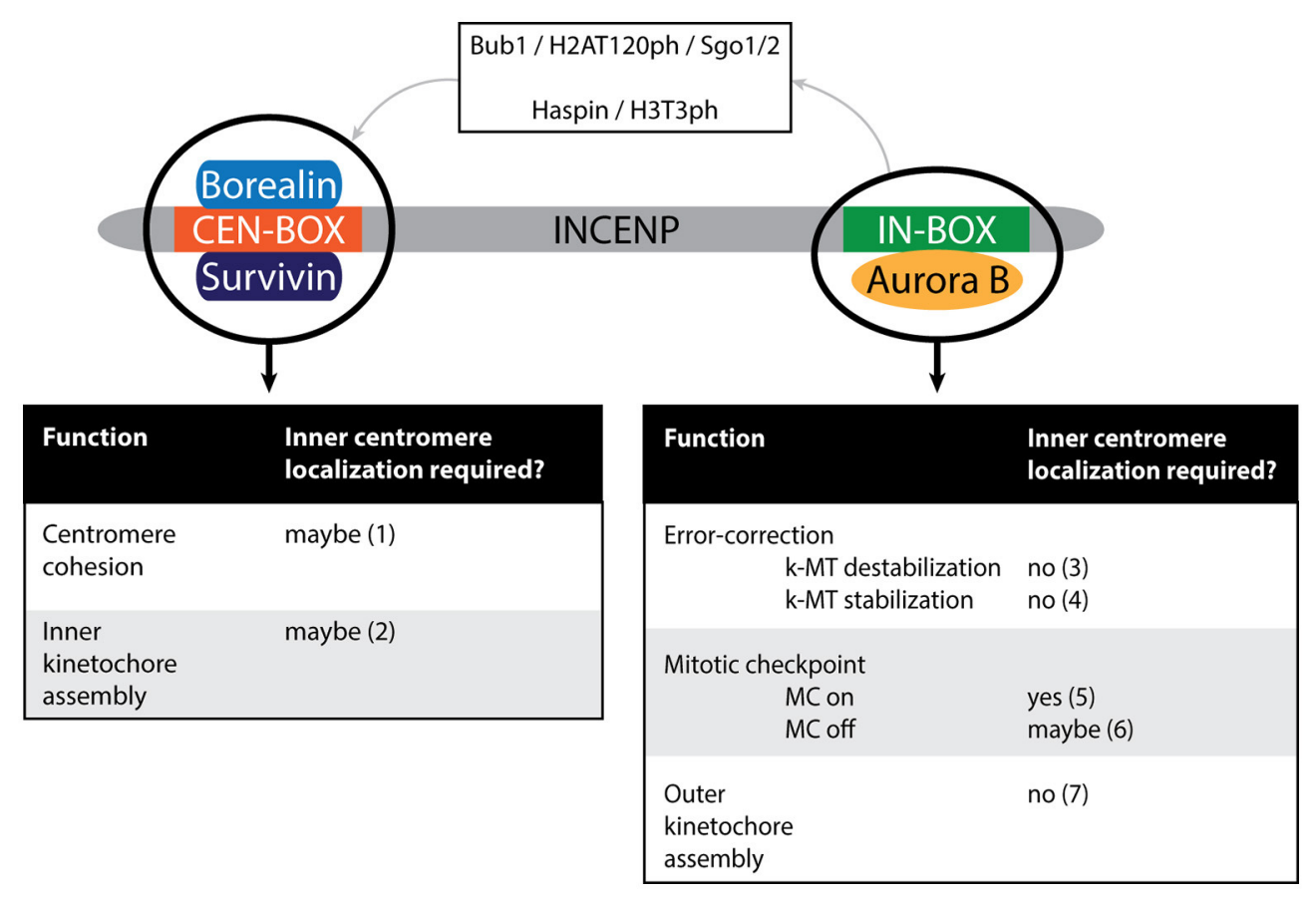

FIGURE 6 | Schematic depiction of the vertebrate CPC. Different modules potentially execute different functions of the CPC: the activity module (Aurora B in conjunction with the IN-box of INCENP) or the CEN module (the CEN-box of INCENP in conjunction with Borealin and Survivin). Note that Aurora B can indirectly affect CEN module dependent functions due to the role of Aurora B in targeting the CPC to the inner centromere (as depicted by the top part of the cartoon). The dependency of each of the functions on inner centromere localization of the CPC is indicated. (1) Not tested in conditions where the CEN module is present but does not localize to the (inner) centromere (Hengeveld et al., 2017). (2) Not tested in conditions where the CEN module is present but does not localize to the (inner) centromere (Haase et al., 2017). (3) Hengeveld et al. (2017). (4) Forcing Aurora B outwards toward the kinetochore-proximal centromere (by expression of CB-INCENP) does not preclude stable KT-MT attachments in cells depleted of Wapl (to maintain cohesion), suggesting inner centromere localization does not contribute to KT-MT stabilization by spatially separating Aurora B from its kinetochore substrates (Hengeveld et al., 2017). (5) Neither CB-INCENP nor Mis12-INCENP can restore mitotic arrest in paclitaxel in the absence of endogenous INCENP (Wheelock et al., 2017). Moreover, mutation of the BIR-domain of Survivin, that prevents inner centromere localization of the CPC, causes a defect in maintaining a paclitaxel-induced arrest (Lens et al., 2006; Yue et al., 2008). (6) MC silencing is disturbed in cells expressing CB-INCENP, but it is unclear if this is due to the close proximity of the Aurora B to its kinetochore substrates or due to constitutive tethering of Aurora B to the outer centromere in this situation (Hengeveld et al., 2017). (7) Haase et al. (2017).

microtubule stabilizing drug paclitaxel (Lens et al., 2006; Yue et al., 2008; Wheelock et al., 2017). While in the latter cells the CPC CEN module is absent, in the former cells the CEN module is present but cannot properly localize, suggesting that either an inner centromere-localized CEN module or Aurora B kinase contributes to a robust mitotic checkpoint response (Figure 6).

If inner centromere localization of the CPC is indeed necessary for chromosome bi-orientation, mitotic checkpoint signaling, centromeric cohesion protection and (inner) kinetochore assembly (Carmena et al., 2012), one would expect severe chromosome segregation defects in cells lacking either Bub1 or Haspin kinase activity, as loss of one of these activities causes a dramatic redistribution of the CPC (Tang et al., 2004; Kelly et al., 2010; Wang et al., 2010; Yamagishi et al., 2010; Ricke et al., 2012). Indeed, mouse embryonic fibroblasts (MEFs) derived from mice deficient in Bub1 kinase activity frequently enter anaphase with misaligned chromosomes, causing neardiploid aneuploidies in approximately $25 \%$ of the cells. The chromosome mis-alignment defects were rescued by expression of CB-INCENP, which relocated the majority of Aurora B to the kinetochore-proximal centromere, suggesting that the pool of Aurora B that localizes at the inter sister chromatid axis when Bub1 activity is impaired, is less efficient in error correction (Tang et al., 2004; Ricke et al., 2012). Remarkably, Haspin KO HeLa cell lines only display a moderate increase in chromosome segregation errors during unperturbed mitosis. However, when mitotic Haspin KO cells were released from a transient monopolar arrest they did display profound mitotic defects, which could be mainly explained by loss of centromeric cohesion. When cohesion was restored by depletion of Wapl, cells were delayed in establishing chromosome bi-orientation, most likely due to mislocalization of the CPC (Zhou et al., 2017). If so, it suggests that the consequences of mislocalized CPC for chromosomal stability are quite mild.

Aneuploidy is a frequent cause of embryonic lethality and a hallmark of cancer (Torres et al., 2008), however Bub1 kinasedead mice develop normally and do not develop tumors (Ricke et al., 2012). Similarly, embryonic development in Haspin KO mice also occurs normally. However, it remains to be determined if MEFs derived from these mice experience chromosome segregation problems, and if these mice eventually develop 
tumors (Shimada et al., 2016). Interestingly, male Bub1 mice are subfertile and Haspin $\mathrm{KO}$ mice show testicular abnormalities (Ricke et al., 2012; Shimada et al., 2016). This could mean that both CPC recruitment arms and/or inner centromere localization of the CPC are needed for proper spermatocyte meiosis and fertility.

\section{CONCLUDING REMARKS}

Based on the data discussed in this review we propose that the evolutionary conservation of two CPC centromere recruitment arms ensures that sufficient amounts of active Aurora B accumulate in the vicinity of kinetochores. We suggest that it makes the KT-MT error correction system robust, thereby making dividing cells more resilient to conditions that would weaken the mitotic checkpoint or that would increase the chance of acquiring erroneous KT-MT attachments, such as disturbances in the geometry of the mitotic spindle (Ertych et al., 2014). In other words, it may safeguard chromosome segregation fidelity in anomalous situations. In addition, inner centromere localization of Aurora B may still be relevant to control the phosphorylation

\section{REFERENCES}

Adams, R. R., Eckley, D. M., Vagnarelli, P., Wheatley, S. P., Gerloff, D. L., Mackay, A. M., et al. (2001a). Human INCENP colocalizes with the Aurora-B/AIRK2 kinase on chromosomes and is overexpressed in tumour cells. Chromosoma 110, 65-74. doi: 10.1007/s004120100130

Adams, R. R., Maiato, H., Earnshaw, W. C., and Carmena, M. (2001b). Essential roles of Drosophila inner centromere protein (INCENP) and aurora B in histone $\mathrm{H} 3$ phosphorylation, metaphase chromosome alignment, kinetochore disjunction, and chromosome segregation. J. Cell Biol. 153, 865-880. doi: $10.1083 /$ jcb.153.4.865

Adams, R. R., Wheatley, S. P., Gouldsworthy, A. M., Kandels-Lewis, S. E., Carmena, M., Smythe, C., et al. (2000). INCENP binds the Aurorarelated kinase AIRK2 and is required to target it to chromosomes, the central spindle and cleavage furrow. Curr. Biol. 10, 1075-1078. doi: 10.1016/S0960-9822(00)00673-4

Akiyoshi, B., Sarangapani, K. K., Powers, A. F., Nelson, C. R., Reichow, S. L., Arellano-Santoyo, H., et al. (2010). Tension directly stabilizes reconstituted kinetochore-microtubule attachments. Nature 468, 576-579. doi: 10.1038/nature09594

Ambrosini, G., Adida, C., and Altieri, D. C. (1997). A novel anti-apoptosis gene, survivin, expressed in cancer and lymphoma. Nat. Med. 3, 917-921. doi: $10.1038 / \mathrm{nm} 0897-917$

Andrews, P. D., Ovechkina, Y., Morrice, N., Wagenbach, M., Duncan, K., Wordeman, L., et al. (2004). Aurora B regulates MCAK at the mitotic centromere. Dev. Cell 6, 253-268. doi: 10.1016/S1534-5807(04)00025-5

Ault, J. G., and Nicklas, R. B. (1989). Tension, microtubule rearrangements, and the proper distribution of chromosomes in mitosis. Chromosoma 98, 33-39. doi: $10.1007 / B F 00293332$

Azuma, Y., Arnaoutov, A., Anan, T., and Dasso, M. (2005). PIASy mediates SUMO-2 conjugation of Topoisomerase-II on mitotic chromosomes. EMBO J. 24, 2172-2182. doi: 10.1038/sj.emboj.7600700

Azuma, Y., Arnaoutov, A., and Dasso, M. (2003). SUMO-2/3 regulates topoisomerase II in mitosis. J. Cell Biol. 163, 477-487. doi: $10.1083 /$ jcb. 200304088

Baron, A. P., von Schubert, C., Cubizolles, F., Siemeister, G., Hitchcock, M., Mengel, A., et al. (2016). Probing the catalytic functions of Bubl kinase using the small molecule inhibitors BAY-320 and BAY-524. Elife 5:e12187. doi: $10.7554 /$ eLife. 12187 status of a number of outer kinetochore substrates, but not all of them. This likely also depends on the regulation of the phosphatase that dephosphorylates a particular substrate. If the antagonizing phosphatase is present at the kinetochore in relatively high amounts then even a slight change in the kinase-substrate distance may have a dramatic effect on the phosphorylation status of the substrate. Finally, the realization that the CEN module of the CPC strengthens centromere cohesion and is involved in inner kinetochore assembly opens up the possibility that the "activity" of the CEN module requires inner centromere localization.

\section{AUTHOR CONTRIBUTIONS}

All authors listed have made a substantial, direct and intellectual contribution to the work, and approved it for publication.

\section{FUNDING}

Work in the laboratory of SL related to this review topic is financially supported by the Dutch Cancer Society (grant 10366).

Basu, J., Bousbaa, H., Logarinho, E., Li, Z., Williams, B. C., Lopes, C., et al. (1999). Mutations in the essential spindle checkpoint gene bub1 cause chromosome missegregation and fail to block apoptosis in Drosophila. J. Cell Biol. 146, 13-28. doi: $10.1083 /$ jcb.146.999.13

Bekier, M. E., Mazur, T., Rashid, M. S., and Taylor, W. R. (2015). Borealin dimerization mediates optimal CPC checkpoint function by enhancing localization to centromeres and kinetochores. Nat. Commun. 6:6775. doi: $10.1038 /$ ncomms7775

Bernard, P., Hardwick, K., and Javerzat, J. P. (1998). Fission yeast bubl is a mitotic centromere protein essential for the spindle checkpoint and the preservation of correct ploidy through mitosis. J. Cell Biol. 143, 1775-1787. doi: $10.1083 /$ jcb.143.7.1775

Bischoff, J. R., Anderson, L., Zhu, Y., Mossie, K., Ng, L., Souza, B., et al. (1998). A homologue of Drosophila aurora kinase is oncogenic and amplified in human colorectal cancers. EMBO J. 17, 3052-3065. doi: 10.1093/emboj/17. 11.3052

Bishop, J. D., and Schumacher, J. M. (2002). Phosphorylation of the carboxyl terminus of inner centromere protein (INCENP) by the Aurora B Kinase stimulates Aurora B kinase activity. J. Biol. Chem. 277, 27577-27580. doi: 10.1074/jbc.C200307200

Blower, M. D. (2016). Centromeric transcription regulates aurora-b localization and activation. Cell Rep. 15, 1624-1633. doi: 10.1016/j.celrep.2016. 04.054

Bohnert, K. A., Chen, J. S., Clifford, D. M., Vander Kooi, C. W., and Gould, K. L. (2009). A link between aurora kinase and Clp1/Cdc14 regulation uncovered by the identification of a fission yeast borealin-like protein. Mol. Biol. Cell 20, 3646-3659. doi: 10.1091/mbc.E09-04-0289

Bolanos-Garcia, V. M., Lischetti, T., Matak-Vinković, D., Cota, E., Simpson, P. J., Chirgadze, D. Y., et al. (2011). Structure of a Blinkin-BUBR1 complex reveals an interaction crucial for kinetochore-mitotic checkpoint regulation via an unanticipated binding Site. Structure 19, 1691-1700. doi: 10.1016/j.str.2011.09.017

Bolton, M. A., Lan, W., Powers, S. E., McCleland, M. L., Kuang, J., and Stukenberg, P. T. (2002). Aurora B kinase exists in a complex with survivin and INCENP and its kinase activity is stimulated by survivin binding and phosphorylation. Mol. Biol. Cell 13, 3064-3077. doi: 10.1091/mbc.E02-02-0092

Boyarchuk, Y., Salic, A., Dasso, M., and Arnaoutov, A. (2007). Bub1 is essential for assembly of the functional inner centromere. J. Cell Biol. 176, 919-928. doi: $10.1083 /$ jcb. 200609044 
Cahill, D. P., Lengauer, C., Yu, J., Riggins, G. J., Willson, J. K., Markowitz, S. D., et al. (1998). Mutations of mitotic checkpoint genes in human cancers. Nature 392, 300-303. doi: 10.1038/32688

Caldas, G. V., and DeLuca, J. G. (2014). KNL1: bringing order to the kinetochore. Chromosoma 123, 169-181. doi: 10.1007/s00412-013-0446-5

Caldas, G. V., Deluca, K. F., and Deluca, J. G. (2013). KNL1 facilitates phosphorylation of outer kinetochore proteins by promoting Aurora B kinase activity. J. Cell Biol. 203, 957-969. doi: 10.1083/jcb.201306054

Campbell, C. S., and Desai, A. (2013). Tension sensing by Aurora B kinase is independent of survivin-based centromere localization. Nature 497, 118-121. doi: 10.1038/nature12057

Carmena, M., Wheelock, M., Funabiki, H., and Earnshaw, W. C. (2012). The chromosomal passenger complex (CPC): from easy rider to the godfather of mitosis. Nat. Rev. Mol. Cell Biol. 13, 789-803. doi: 10.1038/nrm3474

Carretero, M., Ruiz-Torres, M., Rodríguez-Corsino, M., Barthelemy, I., and Losada, A. (2013). Pds5B is required for cohesion establishment and Aurora B accumulation at centromeres. EMBO J. 32, 2938-2949. doi: 10.1038/emboj.2013.230

Chan, C. S., and Botstein, D. (1993). Isolation and characterization of chromosome-gain and increase-in-ploidy mutants in yeast. Genetics 135, 677-691.

Chan, F. L., Marshall, O. J., Saffery, R., Kim, B. W., Earle, E., Choo, K. H., et al. (2012). Active transcription and essential role of RNA polymerase II at the centromere during mitosis. Proc. Natl. Acad. Sci. U.S.A. 109, 1979-1984. doi: 10.1073/pnas.1108705109

Chang, J. L., Chen, T. H., Wang, C. F., Chiang, Y. H., Huang, Y. L., Wong, F. H., et al. (2006). Borealin/Dasra B is a cell cycle-regulated chromosomal passenger protein and its nuclear accumulation is linked to poor prognosis for human gastric cancer. Exp. Cell Res. 312, 962-973. doi: 10.1016/j.yexcr.2005.12.015

Christensen, M. O., Larsen, M. K., Barthelmes, H. U., Hock, R., Andersen, C. L., Kjeldsen, E., et al. (2002). Dynamics of human DNA topoisomerases IIalpha and IIbeta in living cells. J. Cell Biol. 157, 31-44. doi: 10.1083/jcb.200112023

Coelho, P. A., Queiroz-Machado, J., Carmo, A. M., Moutinho-Pereira, S., Maiato, H., and Sunkel, C. E. (2008). Dual role of topoisomerase II in centromere resolution and aurora B activity. PLoS Biol. 6:e207. doi: 10.1371/journal.pbio.0060207

Couturier, A. M., Fleury, H., Patenaude, A. M., Bentley, V. L., Rodrigue, A., Coulombe, Y., et al. (2016). Roles for APRIN (PDS5B) in homologous recombination and in ovarian cancer prediction. Nucleic Acids Res. 44, 10879-10897. doi: 10.1093/nar/gkw921

Cuppen, E., van der Linden, A. M., Jansen, G., and Plasterk, R. H. (2003). Proteins interacting with Caenorhabditis elegans Galpha subunits. Comp. Funct. Genomics 4, 479-491. doi: 10.1002/cfg.318

Dai, J., and Higgins, J. M. (2005). Haspin: a mitotic histone kinase required for metaphase chromosome alignment. Cell Cycle 4, 665-668. doi: $10.4161 /$ cc. 4.5 .1683

Dai, J., Sullivan, B. A., and Higgins, J. M. (2006). Regulation of mitotic chromosome cohesion by Haspin and Aurora B. Dev. Cell 11, 741-750. doi: 10.1016/j.devcel.2006.09.018

Dai, J., Sultan, S., Taylor, S. S., and Higgins, J. M. (2005). The kinase haspin is required for mitotic histone $\mathrm{H} 3 \mathrm{Thr} 3$ phosphorylation and normal metaphase chromosome alignment. Genes Dev. 19, 472-488. doi: 10.1101/gad.1267105

Daum, J. R., Potapova, T. A., Sivakumar, S., Daniel, J. J., Flynn, J. N., Rankin, S., et al. (2011). Cohesion fatigue induces chromatid separation in cells delayed at metaphase. Curr. Biol. 21, 1018-1024. doi: 10.1016/j.cub.2011.05.032

Dawlaty, M. M., Malureanu, L., Jeganathan, K. B., Kao, E., Sustmann, C., Tahk, S., et al. (2008). Resolution of sister centromeres requires RanBP2-mediated SUMOylation of topoisomerase IIalpha. Cell 133, 103-115. doi: 10.1016/j.cell.2008.01.045

De Antoni, A., Maffini, S., Knapp, S., Musacchio, A., and Santaguida, S. (2012). A small-molecule inhibitor of Haspin alters the kinetochore functions of Aurora B. J. Cell Biol. 199, 269-284. doi: 10.1083/jcb.201205119

de Carvalho, C. E., Zaaijer, S., Smolikov, S., Gu, Y., Schumacher, J. M., and Colaiácovo, M. P. (2008). LAB-1 antagonizes the Aurora B kinase in C. Elegans. Genes Dev. 22, 2869-2885. doi: 10.1101/gad.1691208

DeLuca, K. F., Lens, S. M., and DeLuca, J. G. (2011). Temporal changes in Hecl phosphorylation control kinetochore-microtubule attachment stability during mitosis. J. Cell Sci. 124, 622-634. doi: 10.1242/jcs.072629
Díaz-Martínez, L. A., Giménez-Abián, J. F., Azuma, Y., Guacci, V., GiménezMartín, G., Lanier, L. M., et al. (2006). PIASgamma is required for faithful chromosome segregation in human cells. PLoS ONE 1:e53. doi: 10.1371/journal.pone.0000053

Ditchfield, C., Johnson, V. L., Tighe, A., Ellston, R., Haworth, C., Johnson, T., et al. (2003). Aurora B couples chromosome alignment with anaphase by targeting BubR1, Mad2, and Cenp-E to kinetochores. J. Cell Biol. 161, 267-280. doi: $10.1083 /$ jcb.200208091

Earnshaw, W. C., and Heck, M. M. (1985). Localization of topoisomerase II in mitotic chromosomes. J. Cell Biol. 100, 1716-1725. doi: 10.1083/jcb.100.5.1716

Eckley, D. M., Ainsztein, A. M., Mackay, A. M., Goldberg, I. G., and Earnshaw, W. C. (1997). Chromosomal proteins and cytokinesis: patterns of cleavage furrow formation and inner centromere protein positioning in mitotic heterokaryons and mid-anaphase cells. J. Cell Biol. 136, 1169-1183. doi: $10.1083 /$ jcb.136.6.1169

Edgerton, H., Johansson, M., Keifenheim, D., Mukherjee, S., Chacón, J. M., Bachant, J., et al. (2016). A noncatalytic function of the topoisomerase II CTD in Aurora B recruitment to inner centromeres during mitosis. J. Cell Biol. 213, 651-664. doi: 10.1083/jcb.201511080

Ertych, N., Stolz, A., Stenzinger, A., Weichert, W., Kaulfuss, S., Burfeind, P., et al. (2014). Increased microtubule assembly rates influence chromosomal instability in colorectal cancer cells. Nat. Cell Biol. 16, 779-791. doi: $10.1038 /$ ncb2994

Eswaran, J., Patnaik, D., Filippakopoulos, P., Wang, F., Stein, R. L., Murray, J. W., et al. (2009). Structure and functional characterization of the atypical human kinase haspin. Proc. Natl. Acad. Sci. U.S.A. 106, 20198-20203. doi: 10.1073/pnas.0901989106

Fernius, J., and Hardwick, K. G. (2007). Bub1 kinase targets Sgol to ensure efficient chromosome biorientation in budding yeast mitosis. PLoS Genet. 3:e213. doi: 10.1371/journal.pgen.0030213

Fischle, W., Tseng, B. S., Dormann, H. L., Ueberheide, B. M., Garcia, B. A., Shabanowitz, J., et al. (2005). Regulation of HP1-chromatin binding by histone H3 methylation and phosphorylation. Nature 438, 1116-1122. doi: 10.1038 /nature04219

Fowler, K. J., Saffery, R., Kile, B. T., Irvine, D. V., Hudson, D. F., Trowell, H. E., et al. (1998). Genetic mapping of mouse centromere protein (Incenp and Cenpe) genes. Cytogenet. Cell Genet. 82, 67-70. doi: 10.1159/000015066

Francisco, L., Wang, W., and Chan, C. S. (1994). Type 1 protein phosphatase acts in opposition to IpL1 protein kinase in regulating yeast chromosome segregation. Mol. Cell. Biol. 14, 4731-4740. doi: 10.1128/MCB.14.7.4731

Fraser, A. G., James, C., Evan, G. I., and Hengartner, M. O. (1999). Caenorhabditis elegans inhibitor of apoptosis protein (IAP) homologue BIR-1 plays a conserved role in cytokinesis. Curr. Biol. 9, 292-301. doi: 10.1016/S0960-9822(99)80137-7

Gandhi, R., Gillespie, P. J., and Hirano, T. (2006). Human Wapl is a cohesinbinding protein that promotes sister-chromatid resolution in mitotic prophase. Curr. Biol. 16, 2406-2417. doi: 10.1016/j.cub.2006.10.061

Gassmann, R., Carvalho, A., Henzing, A. J., Ruchaud, S., Hudson, D. F., Honda, R., et al. (2004). Borealin: a novel chromosomal passenger required for stability of the bipolar mitotic spindle. J. Cell Biol. 166, 179-191. doi: $10.1083 /$ jcb.200404001

Ghenoiu, C., Wheelock, M. S., and Funabiki, H. (2013). Autoinhibition and Polo-dependent multisite phosphorylation restrict activity of the histone H3 kinase Haspin to mitosis. Mol. Cell 52, 734-745. doi: 10.1016/j.molcel.2013. 10.002

Giet, R., and Glover, D. M. (2001). Drosophila aurora B kinase is required for histone $\mathrm{H} 3$ phosphorylation and condensin recruitment during chromosome condensation and to organize the central spindle during cytokinesis. J. Cell Biol. 152, 669-682. doi: 10.1083/jcb.152.4.669

Goldstein, L. S. (1980). Mechanisms of chromosome orientation revealed by two meiotic mutants in Drosophila melanogaster. Chromosoma 78, 79-111. doi: 10.1007/BF00291909

Gómez, R., Valdeolmillos, A., Parra, M. T., Viera, A., Carreiro, C., Roncal, F., et al. (2007). Mammalian SGO2 appears at the inner centromere domain and redistributes depending on tension across centromeres during meiosis II and mitosis. EMBO Rep. 8, 173-180. doi: 10.1038/sj.embor.7400877

Goto, Y., Yamagishi, Y., Shintomi-Kawamura, M., Abe, M., Tanno, Y., and Watanabe, Y. (2017). Pds5 regulates sister-chromatid cohesion and 
chromosome Bi-orientation through a conserved protein interaction module. Curr. Biol. 27, 1005-1012. doi: 10.1016/j.cub.2017.02.066

Haarhuis, J. H., Elbatsh, A. M., and Rowland, B. D. (2014). Cohesin and its regulation: on the logic of X-shaped chromosomes. Dev. Cell 31, 7-18. doi: 10.1016/j.devcel.2014.09.010

Haarhuis, J. H., Elbatsh, A. M., van den Broek, B., Camps, D., Erkan, H., Jalink, K., et al. (2013). WAPL-mediated removal of cohesin protects against segregation errors and aneuploidy. Curr. Biol. 23, 2071-2077. doi: 10.1016/j.cub.2013.09.003

Haase, J., Bonner, M. K., Halas, H., and Kelly, A. E. (2017). Distinct roles of the chromosomal passenger complex in the detection of and response to errors in kinetochore-microtubule attachment. Dev. Cell 42, 640-654:e5. doi: 10.1016/j.devcel.2017.08.022

Han, A., Lee, K. H., Hyun, S., Lee, N. J., Lee, S. J., Hwang, H., et al. (2011). Methylation-mediated control of aurora kinase B and Haspin with epigenetically modified histone H3 N-terminal peptides. Bioorg. Med. Chem. 19, 2373-2377. doi: 10.1016/j.bmc.2011.02.011

Hanson, K. K., Kelley, A. C., and Bienz, M. (2005). Loss of Drosophila borealin causes polyploidy, delayed apoptosis and abnormal tissue development. Development 132, 4777-4787. doi: 10.1242/dev.02057

Hara, K., Zheng, G., Qu, Q., Liu, H., Ouyang, Z., Chen, Z., et al. (2014). Structure of cohesin subcomplex pinpoints direct shugoshin-Wapl antagonism in centromeric cohesion. Nat. Struct. Mol. Biol. 21, 864-870. doi: $10.1038 / \mathrm{nsmb} .2880$

Hauf, S., Roitinger, E., Koch, B., Dittrich, C. M., Mechtler, K., and Peters, J. M. (2005). Dissociation of cohesin from chromosome arms and loss of arm cohesion during early mitosis depends on phosphorylation of SA2. PLoS Biol. 3:e69. doi: 10.1371/journal.pbio.0030069

Hengeveld, R. C. C., Vromans, M. J. M., Vleugel, M., Hadders, M. A., and Lens, S. M. A. (2017). Inner centromere localization of the CPC maintains centromere cohesion and allows mitotic checkpoint silencing. Nat. Commun. 8:15542. doi: 10.1038/ncomms15542

Hengeveld, R. C., de Boer, H. R., Schoonen, P. M., de Vries, E. G., Lens, S. M., and van Vugt, M. A. (2015). Rif1 is required for resolution of ultrafine DNA bridges in anaphase to ensure genomic stability. Dev. Cell 34, 466-474. doi: 10.1016/j.devcel.2015.06.014

Higgins, J. M. (2001a). Haspin-like proteins: a new family of evolutionarily conserved putative eukaryotic protein kinases. Protein Sci. 10, 1677-1684. doi: $10.1110 /$ ps.49901

Higgins, J. M. (2001b). The Haspin gene: location in an intron of the integrin alphaE gene, associated transcription of an integrin alphaE-derived RNA and expression in diploid as well as haploid cells. Gene 267, 55-69. doi: 10.1016/S0378-1119(01)00387-0

Higgins, J. M. (2003). Structure, function and evolution of haspin and haspinrelated proteins, a distinctive group of eukaryotic protein kinases. Cell. Mol. Life Sci. 60, 446-462. doi: 10.1007/s000180300038

Hindriksen, S., Bramer, A. J., Truong, M. A., Vromans, M. J. M., Post, J. B., Verlaan-Klink, I., et al. (2017). Baculoviral delivery of CRISPR/Cas9 facilitates efficient genome editing in human cells. PLoS ONE 12:e0179514. doi: 10.1371/journal.pone.0179514

Hirota, T., Lipp, J. J., Toh, B. H., and Peters, J. M. (2005). Histone H3 serine 10 phosphorylation by Aurora B causes HP1 dissociation from heterochromatin. Nature 438, 1176-1180. doi: 10.1038/nature04254

Hoffman, D. B., Pearson, C. G., Yen, T. J., Howell, B. J., and Salmon, E. D. (2001). Microtubule-dependent changes in assembly of microtubule motor proteins and mitotic spindle checkpoint proteins at PtK1 kinetochores. Mol. Biol. Cell 12, 1995-2009. doi: 10.1091/mbc.12.7.1995

Honda, R., Körner, R., and Nigg, E. A. (2003). Exploring the functional interactions between Aurora B, INCENP, and survivin in mitosis. Mol. Biol. Cell 14, 3325-3341. doi: 10.1091/mbc.E02-11-0769

Hoyt, M. A., Totis, L., and Roberts, B. T. (1991). S cerevisiae genes required for cell cycle arrest in response to loss of microtubule function. Cell, 66, 507-517. doi: 10.1016/0092-8674(81)90014-3

Huang, H., Feng, J., Famulski, J., Rattner, J. B., Liu, S. T., Kao, G. D., et al. (2007). Tripin/hSgo2 recruits MCAK to the inner centromere to correct defective kinetochore attachments. J. Cell Biol. 177, 413-424. doi: 10.1083/jcb.200701122

Hudson, D. F., Vagnarelli, P., Gassmann, R., and Earnshaw, W. C. (2003). Condensin is required for nonhistone protein assembly and structural integrity of vertebrate mitotic chromosomes. Dev. Cell 5, 323-336. doi: 10.1016/S1534-5807(03)00199-0

Indjeian, V. B., Stern, B. M., and Murray, A. W. (2005). The centromeric protein Sgol is required to sense lack of tension on mitotic chromosomes. Science 307, 130-133. doi: 10.1126/science. 1101366

Jablonski, S. A., Chan, G. K., Cooke, C. A., Earnshaw, W. C., and Yen, T. J. (1998). The hBUB1 and hBUBR1 kinases sequentially assemble onto kinetochores during prophase with hBUBR1 concentrating at the kinetochore plates in mitosis. Chromosoma 107, 386-396. doi: 10.1007/s004120050322

Jambhekar, A., Emerman, A. B., Schweidenback, C. T., and Blower, M. D. (2014). RNA stimulates Aurora B kinase activity during mitosis. PLoS ONE 9:e100748. doi: 10.1371/journal.pone. 0100748

Jeyaprakash, A. A., Basquin, C., Jayachandran, U., and Conti, E. (2011). Structural basis for the recognition of phosphorylated histone $\mathrm{h} 3$ by the survivin subunit of the chromosomal passenger complex. Structure 19, 1625-1634. doi: 10.1016/j.str.2011.09.002

Jeyaprakash, A. A., Klein, U. R., Lindner, D., Ebert, J., Nigg, E. A., and Conti, E. (2007). Structure of a Survivin-Borealin-INCENP core complex reveals how chromosomal passengers travel together. Cell 131, 271-285. doi: 10.1016/j.cell.2007.07.045

Jones, G., Jones, D., Zhou, L., Steller, H., and Chu, Y. (2000). Deterin, a new inhibitor of apoptosis from Drosophila melanogaster. J. Biol. Chem. 275, 22157-22165. doi: 10.1074/jbc.M000369200

Kaitna, S., Mendoza, M., Jantsch-Plunger, V., and Glotzer, M. (2000). Incenp and an aurora-like kinase form a complex essential for chromosome segregation and efficient completion of cytokinesis. Curr. Biol. 10, 1172-1181. doi: 10.1016/S0960-9822(00)00721-1

Kang, J., Cheeseman, I. M., Kallstrom, G., Velmurugan, S., Barnes, G., and Chan, C. S. (2001). Functional cooperation of Dam1, Ipl1, and the inner centromere protein (INCENP)-related protein Sli15 during chromosome segregation. $J$. Cell Biol. 155, 763-774. doi: 10.1083/jcb.200105029

Karimi-Ashtiyani, R., and Houben, A. (2013). In vitro phosphorylation of histone $\mathrm{H} 3$ at threonine 3 by Arabidopsis haspin is strongly influenced by posttranslational modifications of adjacent amino acids. Mol. Plant 6, 574-576. doi: $10.1093 / \mathrm{mp} / \mathrm{sss} 149$

Kawashima, S. A., Tsukahara, T., Langegger, M., Hauf, S., Kitajima, T. S., and Watanabe, Y. (2007). Shugoshin enables tension-generating attachment of kinetochores by loading Aurora to centromeres. Genes Dev. 21, 420-435. doi: 10.1101/gad.1497307

Kawashima, S. A., Yamagishi, Y., Honda, T., Ishiguro, K., and Watanabe, Y. (2010). Phosphorylation of H2A by Bub1 prevents chromosomal instability through localizing shugoshin. Science 327, 172-177. doi: 10.1126/science.1180189

Kelly, A. E., Ghenoiu, C., Xue, J. Z., Zierhut, C., Kimura, H., and Funabiki, H. (2010). Survivin reads phosphorylated histone $\mathrm{H} 3$ threonine 3 to activate the mitotic kinase Aurora B. Science 330, 235-239. doi: 10.1126/science.1189505

Kelly, A. E., Sampath, S. C., Maniar, T. A., Woo, E. M., Chait, B. T., and Funabiki, H. (2007). Chromosomal enrichment and activation of the aurora B pathway are coupled to spatially regulate spindle assembly. Dev. Cell 12, 31-43. doi: 10.1016/j.devcel.2006.11.001

Kerrebrock, A. W., Miyazaki, W. Y., Birnby, D., and Orr-Weaver, T. L. (1992). The Drosophila mei-S332 gene promotes sister-chromatid cohesion in meiosis following kinetochore differentiation. Genetics 130, 827-841.

Kiburz, B. M., Amon, A., and Marston, A. L. (2008). Shugoshin promotes sister kinetochore biorientation in Saccharomyces cerevisiae. Mol. Biol. Cell 19, 1199-1209. doi: 10.1091/mbc.E07-06-0584

Kim, J. H., Kang, J. S., and Chan, C. S. (1999). Sli15 associates with the ipl1 protein kinase to promote proper chromosome segregation in Saccharomyces cerevisiae. J. Cell Biol. 145, 1381-1394. doi: 10.1083/jcb.145.7.1381

Kimura, M., Matsuda, Y., Yoshioka, T., Sumi, N., and Okano, Y. (1998). Identification and characterization of STK12/Aik2: a human gene related to aurora of Drosophila and yeast IPL1. Cytogenet. Cell Genet. 82, 147-152. doi: $10.1159 / 000015089$

Kireeva, N., Lakonishok, M., Kireev, I., Hirano, T., and Belmont, A. S. (2004). Visualization of early chromosome condensation: a hierarchical folding, axial glue model of chromosome structure. J. Cell Biol. 166, 775-785. doi: 10.1083/jcb.200406049

Kitajima, T. S., Hauf, S., Ohsugi, M., Yamamoto, T., and Watanabe, Y. (2005). Human Bubl defines the persistent cohesion site along the mitotic 
chromosome by affecting Shugoshin localization. Curr. Biol. 15, 353-359. doi: 10.1016/j.cub.2004.12.044

Kitajima, T. S., Kawashima, S. A., and Watanabe, Y. (2004). The conserved kinetochore protein shugoshin protects centromeric cohesion during meiosis. Nature 427, 510-517. doi: 10.1038/nature02312

Kitajima, T. S., Sakuno, T., Ishiguro, K., Iemura, S., Natsume, T., Kawashima, S. A., et al. (2006). Shugoshin collaborates with protein phosphatase $2 \mathrm{~A}$ to protect cohesin. Nature 441, 46-52. doi: 10.1038/nature04663

Kiyomitsu, T., Murakami, H., and Yanagida, M. (2011). Protein interaction domain mapping of human kinetochore protein Blinkin reveals a consensus motif for binding of spindle assembly checkpoint proteins Bub1 and BubR1. Mol. Cell. Biol. 31, 998-1011. doi: 10.1128/MCB.00815-10

Kiyomitsu, T., Obuse, C., and Yanagida, M. (2007). Human Blinkin/AF15q14 is required for chromosome alignment and the mitotic checkpoint through direct interaction with Bub1 and BubR1. Dev. Cell 13, 663-676. doi: 10.1016/j.devcel.2007.09.005

Klein, U. R., Nigg, E. A., and Gruneberg, U. (2006). Centromere targeting of the chromosomal passenger complex requires a ternary subcomplex of Borealin, Survivin, and the N-terminal domain of INCENP. Mol. Biol. Cell 17, 2547-2558. doi: 10.1091/mbc.E05-12-1133

Krenn, V., and Musacchio, A. (2015). The Aurora B kinase in chromosome Bi-orientation and spindle checkpoint signaling. Front. Oncol. 5:225. doi: 10.3389/fonc. 2015.00225

Krenn, V., Wehenkel, A., Li, X., Santaguida, S., and Musacchio, A. (2012). Structural analysis reveals features of the spindle checkpoint kinase Bubl-kinetochore subunit Knl1 interaction. J. Cell Biol. 196, 451-467. doi: $10.1083 /$ jcb.201110013

Kruse, T., Zhang, G., Larsen, M. S., Lischetti, T., Streicher, W., Kragh Nielsen, T., et al. (2013). Direct binding between BubR1 and B56PP2A phosphatase complexes regulate mitotic progression. J. Cell Sci. 126, 1086-1092. doi: 10.1242/jcs.122481

Kueng, S., Hegemann, B., Peters, B. H., Lipp, J. J., Schleiffer, A., Mechtler, K., et al. (2006). Wapl controls the dynamic association of cohesin with chromatin. Cell 127, 955-967. doi: 10.1016/j.cell.2006.09.040

Lee, J., Kitajima, T. S., Tanno, Y., Yoshida, K., Morita, T., Miyano, T., et al. (2008). Unified mode of centromeric protection by shugoshin in mammalian oocytes and somatic cells. Nat. Cell Biol. 10, 42-52. doi: 10.1038/ncb1667

Lee, M. T., and Bachant, J. (2009). SUMO modification of DNA topoisomerase II: trying to get a CENse of it all. DNA Repair. 8, 557-568. doi: 10.1016/j.dnarep.2009.01.004

Lee, N. R., Kim, H. S., Kim, Y. S., Kwon, M. H., Choi, K. S., and Lee, C. W. (2014). Regulation of the subcellular shuttling of Sgol between centromeres and chromosome arms by Aurora B-mediated phosphorylation. Biochem. Biophys. Res. Commun. 454, 429-435. doi: 10.1016/j.bbrc.2014.10.103

Lens, S. M., Rodriguez, J. A., Vader, G., Span, S. W., Giaccone, G., and Medema, R. H. (2006). Uncoupling the central spindle-associated function of the chromosomal passenger complex from its role at centromeres. Mol. Biol. Cell 17, 1897-1909. doi: 10.1091/mbc.E05-08-0727

Leverson, J. D., Huang, H. K., Forsburg, S. L., and Hunter, T. (2002). The Schizosaccharomyces pombe aurora-related kinase Ark1 interacts with the inner centromere protein Picl and mediates chromosome segregation and cytokinesis. Mol. Biol. Cell 13, 1132-1143. doi: 10.1091/mbc.01-07-0330

Li, F., and Altieri, D. C. (1999). The cancer antiapoptosis mouse survivin gene: characterization of locus and transcriptional requirements of basal and cell cycle-dependent expression. Cancer Res. 59, 3143-3151.

Li, F., Ambrosini, G., Chu, E. Y., Plescia, J., Tognin, S., Marchisio, P. C., et al. (1998). Control of apoptosis and mitotic spindle checkpoint by survivin. Nature 396, 580-584. doi: 10.1038/25141

Li, F., Flanary, P. L., Altieri, D. C., and Dohlman, H. G. (2000). Cell division regulation by BIR1, a member of the inhibitor of apoptosis family in yeast. J. Biol. Chem. 275, 6707-6711. doi: 10.1074/jbc.275.10.6707

Liu, D., Vader, G., Vromans, M. J., Lampson, M. A., and Lens, S. M. (2009). Sensing chromosome bi-orientation by spatial separation of aurora B kinase from kinetochore substrates. Science 323, 1350-1353. doi: 10.1126/science.1167000

Liu, D., Vleugel, M., Backer, C. B., Hori, T., Fukagawa, T., Cheeseman, I. M., et al. (2010). Regulated targeting of protein phosphatase 1 to the outer kinetochore by KNL1 opposes Aurora B kinase. J. Cell Biol. 188, 809-820. doi: $10.1083 /$ jcb. 201001006
Liu, H., Jia, L., and Yu, H. (2013a). Phospho-H2A and cohesin specify distinct tension-regulated Sgol pools at kinetochores and inner centromeres. Curr. Biol. 23, 1927-1933. doi: 10.1016/j.cub.2013.07.078

Liu, H., Qu, Q., Warrington, R., Rice, A., Cheng, N., and Yu, H. (2015). Mitotic transcription installs Sgol at centromeres to coordinate chromosome segregation. Mol. Cell 59, 426-436. doi: 10.1016/j.molcel.2015.06.018

Liu, H., Rankin, S., and Yu, H. (2013b). Phosphorylation-enabled binding of SGO1-PP2A to cohesin protects sororin and centromeric cohesion during mitosis. Nat. Cell Biol. 15, 40-49. doi: 10.1038/ncb2637

Llano, E., Gómez, R., Gutiérrez-Caballero, C., Herrán, Y., Sánchez-Martín, M., Vázquez-Quiñones, L., et al. (2008). Shugoshin-2 is essential for the completion of meiosis but not for mitotic cell division in mice. Genes Dev. 22, 2400-2413. doi: $10.1101 /$ gad.475308

London, N., Ceto, S., Ranish, J. A., and Biggins, S. (2012). Phosphoregulation of Spc105 by Mps1 and PP1 regulates Bub1 localization to kinetochores. Curr. Biol. 22, 900-906. doi: 10.1016/j.cub.2012.03.052

Mackay, A. M., Eckley, D. M., Chue, C., and Earnshaw, W. C. (1993). Molecular analysis of the INCENPs (inner centromere proteins): separate domains are required for association with microtubules during interphase and with the central spindle during anaphase. J. Cell Biol. 123, 373-385. doi: $10.1083 /$ jcb.123.2.373

Maresca, T. J., and Salmon, E. D. (2009). Intrakinetochore stretch is associated with changes in kinetochore phosphorylation and spindle assembly checkpoint activity. J. Cell Biol. 184, 373-381. doi: 10.1083/jcb.200808130

Markaki, Y., Christogianni, A., Politou, A. S., and Georgatos, S. D. (2009). Phosphorylation of histone $\mathrm{H} 3$ at $\mathrm{Thr} 3$ is part of a combinatorial pattern that marks and configures mitotic chromatin. J. Cell Sci. 122, 2809-2819. doi: $10.1242 /$ jcs.043810

McGuinness, B. E., Hirota, T., Kudo, N. R., Peters, J. M., and Nasmyth, K. (2005). Shugoshin prevents dissociation of cohesin from centromeres during mitosis in vertebrate cells. PLoS Biol. 3:e86. doi: 10.1371/journal.pbio.00 30086

McNulty, S. M., Sullivan, L. L., and Sullivan, B. A. (2017). Human centromeres produce chromosome-specific and array-specific alpha satellite transcripts that are complexed with CENP-A and CENP-C. Dev. Cell 42, 226-240.e6. doi: 10.1016/j.devcel.2017.07.001

Meppelink, A., Kabeche, L., Vromans, M. J., Compton, D. A., and Lens, S. M. (2015). Shugoshin-1 balances Aurora B kinase activity via PP2A to promote chromosome bi-orientation. Cell Rep. 11, 508-515. doi: 10.1016/j.celrep.2015.03.052

Molina, O., Vargiu, G., Abad, M. A., Zhiteneva, A., Jeyaprakash, A. A., Masumoto, H., et al. (2016). Epigenetic engineering reveals a balance between histone modifications and transcription in kinetochore maintenance. Nat. Commun. 7:13334. doi: 10.1038/ncomms13334

Moore, D. P., Page, A. W., Tang, T. T., Kerrebrock, A. W., and Orr-Weaver, T. L. (1998). The cohesion protein MEI-S332 localizes to condensed meiotic and mitotic centromeres until sister chromatids separate. J. Cell Biol. 140, 1003-1012. doi: 10.1083/jcb.140.5.1003

Morishita, J., Matsusaka, T., Goshima, G., Nakamura, T., Tatebe, H., and Yanagida, M. (2001). Bir1/Cut17 moving from chromosome to spindle upon the loss of cohesion is required for condensation, spindle elongation and repair. Genes Cells 6, 743-763. doi: 10.1046/j.1365-2443.2001.00459.x

Moyle, M. W., Kim, T., Hattersley, N., Espeut, J., Cheerambathur, D. K., Oegema, K., et al. (2014). A Bub1-Mad1 interaction targets the Mad1-Mad2 complex to unattached kinetochores to initiate the spindle checkpoint. J. Cell Biol. 204, 647-657. doi: 10.1083/jcb.201311015

Murphy, C. R., Sabel, J. L., Sandler, A. D., and Dagle, J. M. (2002). Survivin mRNA is down-regulated during early Xenopus laevis embryogenesis. Dev. Dyn. 225, 597-601. doi: 10.1002/dvdy.10194

Musacchio, A. (2015). The molecular biology of spindle assembly checkpoint signaling dynamics. Curr. Biol. 25, R1002-R1018. doi: 10.1016/j.cub.2015.10.050

Musacchio, A., and Desai, A. (2017). A molecular view of kinetochore assembly and function. Biology 6:5. doi: 10.3390/biology6010005

Nakajima, Y., Tyers, R. G., Wong, C. C., Yates, J. R., Drubin, D. G., and Barnes, G. (2009). Nbllp: a Borealin/Dasra/CSC-1-like protein essential for Aurora/Ipl1 complex function and integrity in Saccharomyces cerevisiae. Mol. Biol. Cell 20, 1772-1784. doi: 10.1091/mbc.E08-10-1011 
Nespoli, A., Vercillo, R., di Nola, L., Diani, L., Giannattasio, M., Plevani, P., et al. (2006). Alk1 and Alk2 are two new cell cycle-regulated haspin-like proteins in budding yeast. Cell Cycle 5, 1464-1471. doi: 10.4161/cc.5.13.2914

Nguyen, A. L., Gentilello, A. S., Balboula, A. Z., Shrivastava, V., Ohring, J., and Schindler, K. (2014). Phosphorylation of threonine 3 on histone H3 by haspin kinase is required for meiosis I in mouse oocytes. J. Cell Sci. 127, 5066-5078. doi: $10.1242 /$ jcs. 158840

Nicklas, R. B., and Koch, C. A. (1969). Chromosome micromanipulation. 3. Spindle fiber tension and the reorientation of mal-oriented chromosomes. J. Cell Biol. 43, 40-50. doi: 10.1083/jcb.43.1.40

Niedzialkowska, E., Wang, F., Porebski, P. J., Minor, W., Higgins, J. M., and Stukenberg, P. T. (2012). Molecular basis for phosphospecific recognition of histone $\mathrm{H} 3$ tails by Survivin paralogues at inner centromeres. Mol. Biol. Cell 23, 1457-1466. doi: 10.1091/mbc.E11-11-0904

Nijenhuis, W., Vallardi, G., Teixeira, A., Kops, G. J., and Saurin, A. T. (2014). Negative feedback at kinetochores underlies a responsive spindle checkpoint signal. Nat. Cell Biol. 16, 1257-1264. doi: 10.1038/ncb3065

Nitiss, J. L. (2009). DNA topoisomerase II and its growing repertoire of biological functions. Nat. Rev. Cancer 9, 327-337. doi: 10.1038/nrc2608

Niwa, H., Abe, K., Kunisada, T., and Yamamura, K. (1996). Cell-cycle-dependent expression of the STK-1 gene encoding a novel murine putative protein kinase. Gene 169, 197-201. doi: 10.1016/0378-1119(95)00809-8

Oegema, K., Desai, A., Rybina, S., Kirkham, M., and Hyman, A. A. (2001). Functional analysis of kinetochore assembly in Caenorhabditis elegans. J. Cell Biol. 153, 1209-1226. doi: 10.1083/jcb.153.6.1209

Ohta, S., Montaño-Gutierrez, L. F., de Lima Alves, F., Ogawa, H., Toramoto, I., Sato, N., et al. (2016). Proteomics analysis with a nano random forest approach reveals novel functional interactions regulated by SMC complexes on mitotic chromosomes. Mol. Cell. Proteomics 15, 2802-2818. doi: 10.1074/mcp.M116.057885

Ouyang, B., Lan, Z., Meadows, J., Pan, H., Fukasawa, K., Li, W., et al. (1998). Human Bub1: a putative spindle checkpoint kinase closely linked to cell proliferation. Cell Growth Differ. 9, 877-885

Pangilinan, F., Li, Q., Weaver, T., Lewis, B. C., Dang, C. V., and Spencer, F. (1997). Mammalian BUB1 protein kinases: map positions and in vivo expression. Genomics 46, 379-388. doi: 10.1006/geno.1997.5068

Peckham, M., and Knight, P. J. (2009). When a predicted coiled coil is really a single a-helix, in myosin and other proteins. Soft Matter 5, 2493-2503. doi: 10.1039/b822339d

Peplowska, K., Wallek, A. U., and Storchova, Z. (2014). Sgol regulates both condensin and Ipl1/Aurora B to promote chromosome biorientation. PLoS Genet. 10:e1004411. doi: 10.1371/journal.pgen.1004411

Petersen, J., Paris, J., Willer, M., Philippe, M., and Hagan, I. M. (2001). The S. pombe aurora-related kinase Ark1 associates with mitotic structures in a stage dependent manner and is required for chromosome segregation. J. Cell Sci., 114, 4371-4384.

Primorac, I., Weir, J. R., Chiroli, E., Gross, F., Hoffmann, I., van Gerwen, S., et al. (2013). Bub3 reads phosphorylated MELT repeats to promote spindle assembly checkpoint signaling. Elife 2:e01030. doi: 10.7554/eLife.01030

Qian, J., Beullens, M., Huang, J., De Munter, S., Lesage, B., and Bollen, M. (2015). Cdk1 orders mitotic events through coordination of a chromosome-associated phosphatase switch. Nat. Commun. 6:10215. doi: 10.1038/ncomms10215

Qian, J., Beullens, M., Lesage, B., and Bollen, M. (2013). Aurora B defines its own chromosomal targeting by opposing the recruitment of the phosphatase scaffold Repo-Man. Curr. Biol. 23, 1136-1143. doi: 10.1016/j.cub.2013.05.017

Qian, J., Lesage, B., Beullens, M., Van Eynde, A., and Bollen, M. (2011). PP1/Repoman dephosphorylates mitotic histone $\mathrm{H} 3$ at $\mathrm{T} 3$ and regulates chromosomal aurora B targeting. Curr. Biol. 21, 766-773. doi: 10.1016/j.cub.2011.03.047

Rabitsch, K. P., Gregan, J., Schleiffer, A., Javerzat, J. P., Eisenhaber, F., and Nasmyth, K. (2004). Two fission yeast homologs of Drosophila Mei-S332 are required for chromosome segregation during meiosis I and II. Curr. Biol. 14, 287-301. doi: 10.1016/j.cub.2004.01.051

Rajagopalan, S., and Balasubramanian, M. K. (1999). S. pombe Pbhlp: an inhibitor of apoptosis domain containing protein is essential for chromosome segregation. FEBS Lett. 460, 187-90. doi: 10.1016/S0014-5793(99)01329-0

Rattner, J. B., Hendzel, M. J., Furbee, C. S., Muller, M. T., and Bazett-Jones, D. P. (1996). Topoisomerase II alpha is associated with the mammalian centromere in a cell cycle- and species-specific manner and is required for proper centromere/kinetochore structure. J. Cell Biol. 134, 1097-1107. doi: $10.1083 /$ jcb.134.5.1097

Reich, A., Yanai, A., Mesilaty-Gross, S., Chen-Moses, A., Wides, R., and Motro, B. (1999). Cloning, mapping, and expression of ial, a novel Drosophila member of the Ipl1/aurora mitotic control kinase family. DNA Cell Biol. 18, 593-603. doi: 10.1089/104454999315141

Resnick, T. D., Satinover, D. L., MacIsaac, F., Stukenberg, P. T., Earnshaw, W. C., Orr-Weaver, T. L., et al. (2006). INCENP and Aurora B promote meiotic sister chromatid cohesion through localization of the Shugoshin MEI-S332 in Drosophila. Dev. Cell 11, 57-68. doi: 10.1016/j.devcel.2006.04.021

Ricke, R. M., Jeganathan, K. B., Malureanu, L., Harrison, A. M., and Van Deursen, J. M. (2012). Bub1 kinase activity drives error correction and mitotic checkpoint control but not tumor suppression. J. Cell Biol. 199, 931-949. doi: $10.1083 /$ jcb.201205115

Riedel, C. G., Katis, V. L., Katou, Y., Mori, S., Itoh, T., Helmhart, W., et al. (2006) Protein phosphatase $2 \mathrm{~A}$ protects centromeric sister chromatid cohesion during meiosis I. Nature 441, 53-61. doi: 10.1038/nature04664

Rivera, T., Ghenoiu, C., Rodríguez-Corsino, M., Mochida, S., Funabiki, H., and Losada, A. (2012). Xenopus Shugoshin 2 regulates the spindle assembly pathway mediated by the chromosomal passenger complex. EMBO J. 31, 1467-1479. doi: 10.1038/emboj.2012.4

Rivera, T., and Losada, A. (2009). Shugoshin regulates cohesion by driving relocalization of PP2A in Xenopus extracts. Chromosoma 118, 223-233. doi: 10.1007/s00412-008-0190-4

Roberts, B. T., Farr, K. A., and Hoyt, M. A. (1994). The Saccharomyces cerevisiae checkpoint gene BUB1 encodes a novel protein kinase. Mol. Cell. Biol. 14, 8282-8291. doi: 10.1128/MCB.14.12.8282

Romano, A., Guse, A., Krascenicova, I., Schnabel, H., Schnabel, R., and Glotzer, M. (2003). CSC-1: a subunit of the Aurora B kinase complex that binds to the survivin-like protein BIR-1 and the incenp-like protein ICP-1. J. Cell Biol. 161, 229-236. doi: 10.1083/jcb.200207117

Saffery, R., Irvine, D. V., Kile, B. T., Hudson, D. F., Cutts, S. M., and Choo, K. H. (1999). Cloning, expression, and promoter structure of a mammalian inner centromere protein (INCENP). Mamm. Genome 10, 415-418. doi: 10.1007/s003359901014

Salic, A., Waters, J. C., and Mitchison, T. J. (2004). Vertebrate shugoshin links sister centromere cohesion and kinetochore microtubule stability in mitosis. Cell 118, 567-578. doi: 10.1016/j.cell.2004.08.016

Salimian, K. J., Ballister, E. R., Smoak, E. M., Wood, S., Panchenko, T., Lampson, M. A., et al. (2011). Feedback control in sensing chromosome biorientation by the Aurora B kinase. Curr. Biol. 21, 1158-1165. doi: 10.1016/j.cub.2011. 06.015

Samejima, K., Platani, M., Wolny, M., Ogawa, H., Vargiu, G., Knight, P. J., et al. (2015). The Inner Centromere Protein (INCENP) Coil Is a Single $\alpha$ Helix (SAH) Domain that binds directly to microtubules and is important for chromosome passenger complex (CPC) localization and function in mitosis. J. Biol. Chem. 290, 21460-21472. doi: 10.1074/jbc.M115.645317

Samejima, K., Samejima, I., Vagnarelli, P., Ogawa, H., Vargiu, G., Kelly, D. A., et al. (2012). Mitotic chromosomes are compacted laterally by KIF4 and condensin and axially by topoisomerase II $\alpha$. J. Cell Biol. 199, 755-770. doi: $10.1083 /$ jcb.201202155

Sampath, S. C., Ohi, R., Leismann, O., Salic, A., Pozniakovski, A., and Funabiki, H. (2004). The chromosomal passenger complex is required for chromatininduced microtubule stabilization and spindle assembly. Cell 118, 187-202. doi: 10.1016/j.cell.2004.06.026

Santaguida, S., and Musacchio, A. (2009). The life and miracles of kinetochores. EMBO J. 28, 2511-2531. doi: 10.1038/emboj.2009.173

Santaguida, S., Vernieri, C., Villa, F., Ciliberto, A., and Musacchio, A. (2011). Evidence that Aurora B is implicated in spindle checkpoint signalling independently of error correction. EMBO J. 30, 1508-1519. doi: 10.1038/emboj.2011.70

Saurin, A. T., van der Waal, M. S., Medema, R. H., Lens, S. M., and Kops, G. J. (2011). Aurora B potentiates Mps1 activation to ensure rapid checkpoint establishment at the onset of mitosis. Nat. Commun. 2:316. doi: $10.1038 /$ ncomms 1319

Schumacher, J. M., Golden, A., and Donovan, P. J. (1998). AIR-2: An Aurora/Ipl1-related protein kinase associated with chromosomes and midbody microtubules is required for polar body extrusion and 
cytokinesis in Caenorhabditis elegans embryos. J. Cell Biol. 143, 1635-1646. doi: $10.1083 /$ jcb.143.6.1635

Schwab, M. S., Roberts, B. T., Gross, S. D., Tunquist, B. J., Taieb, F. E., Lewellyn, A. L., et al. (2001). Bubl is activated by the protein kinase p90(Rsk) during Xenopus oocyte maturation. Curr. Biol. 11, 141-150. doi: 10.1016/S0960-9822(01)00045-8

Sessa, F., Mapelli, M., Ciferri, C., Tarricone, C., Areces, L. B., Schneider, T. R., et al. (2005). Mechanism of Aurora B activation by INCENP and inhibition by hesperadin. Mol. Cell 18, 379-391. doi: 10.1016/j.molcel.2005.03.031

Sharp-Baker, H., and Chen, R. H. (2001). Spindle checkpoint protein Bubl is required for kinetochore localization of Mad1, Mad2, Bub3, and CENPE, independently of its kinase activity. J. Cell Biol. 153, 1239-1250. doi: $10.1083 /$ jcb.153.6.1239

Shepperd, L. A., Meadows, J. C., Sochaj, A. M., Lancaster, T. C., Zou, J., Buttrick, G. J., et al. (2012). Phosphodependent recruitment of Bub1 and Bub3 to Spc7/KNL1 by Mph1 kinase maintains the spindle checkpoint. Curr. Biol. 22, 891-899. doi: 10.1016/j.cub.2012.03.051

Shimada, M., Goshima, T., Matsuo, H., Johmura, Y., Haruta, M., Murata, K., et al. (2016). Essential role of autoactivation circuitry on Aurora B-mediated H2AX-pS121 in mitosis. Nat. Commun. 7:12059. doi: 10.1038/ncomms12059

Shindo, M., Nakano, H., Kuroyanagi, H., Shirasawa, T., Mihara, M., Gilbert, D. J., et al. (1998). cDNA cloning, expression, subcellular localization, and chromosomal assignment of mammalian aurora homologues, aurora-related kinase (ARK) 1 and 2. Biochem. Biophys. Res. Commun. 244, 285-292. doi: 10.1006/bbrc. 1998.8250

Skoufias, D. A., Andreassen, P. R., Lacroix, F. B., Wilson, L., and Margolis, R. L. (2001). Mammalian mad2 and bub1/bubR1 recognize distinct spindleattachment and kinetochore-tension checkpoints. Proc. Natl. Acad. Sci. U.S.A. 98, 4492-4497. doi: 10.1073/pnas.081076898

Skoufias, D. A., Mollinari, C., Lacroix, F. B., and Margolis, R. L. (2000). Human survivin is a kinetochore-associated passenger protein. J. Cell Biol. 151, 1575-1582. doi: 10.1083/jcb.151.7.1575

Speliotes, E. K., Uren, A., Vaux, D., and Horvitz, H. R. (2000). The survivinlike C. elegans BIR-1 protein acts with the Aurora-like kinase AIR-2 to affect chromosomes and the spindle midzone. Mol. Cell 6, 211-223. doi: 10.1016/S1097-2765(00)00023-X

Stukenberg, P. T., Lustig, K. D., McGarry, T. J., King, R. W., Kuang, J., and Kirschner, M. W. (1997). Systematic identification of mitotic phosphoproteins. Curr. Biol. 7, 338-348. doi: 10.1016/S0960-9822(06)00157-6

Suijkerbuijk, S. J., Vleugel, M., Teixeira, A., and Kops, G. J. (2012). Integration of kinase and phosphatase activities by BUBR1 ensures formation of stable kinetochore-microtubule attachments. Dev. Cell 23, 745-755. doi: 10.1016/j.devcel.2012.09.005

Sullivan, B. A., and Karpen, G. H. (2004). Centromeric chromatin exhibits a histone modification pattern that is distinct from both euchromatin and heterochromatin. Nat. Struct. Mol. Biol. 11, 1076-1083. doi: 10.1038/nsmb845

Suzuki, A., Badger, B. L., Wan, X., DeLuca, J. G., and Salmon, E. D. (2014). The architecture of CCAN proteins creates a structural integrity to resist spindle forces and achieve proper Intrakinetochore stretch. Dev. Cell 30, 717-730. doi: 10.1016/j.devcel.2014.08.003

Szafer-Glusman, E., Fuller, M. T., and Giansanti, M. G. (2011). Role of Survivin in cytokinesis revealed by a separation-of-function allele. Mol. Biol. Cell 22, 3779-3790. doi: 10.1091/mbc.E11-06-0569

Tanaka, H., Iguchi, N., Nakamura, Y., Kohroki, J., de Carvalho, C. E., and Nishimune, Y. (2001). Cloning and characterization of human haspin gene encoding haploid germ cell-specific nuclear protein kinase. Mol. Hum. Reprod. 7, 211-218. doi: 10.1093/molehr/7.3.211

Tanaka, H., Yoshimura, Y., Nozaki, M., Yomogida, K., Tsuchida, J., Tosaka, Y., et al. (1999). Identification and characterization of a haploid germ cell-specific nuclear protein kinase (Haspin) in spermatid nuclei and its effects on somatic cells. J. Biol. Chem. 274, 17049-17057. doi: 10.1074/jbc.274.24.17049

Tanaka, T. U., Rachidi, N., Janke, C., Pereira, G., Galova, M., Schiebel, E., et al. (2002). Evidence that the Ipl1-Sli15 (Aurora kinase-INCENP) complex promotes chromosome bi-orientation by altering kinetochore-spindle pole connections. Cell 108, 317-329. doi: 10.1016/S0092-8674(02)00633-5

Tang, Z., Sun, Y., Harley, S. E., Zou, H., and Yu, H. (2004). Human Bub1 protects centromeric sister-chromatid cohesion through Shugoshin during mitosis. Proc. Natl. Acad. Sci. U.S.A. 101, 18012-18017. doi: 10.1073/pnas.0408600102
Tanno, Y., Kitajima, T. S., Honda, T., Ando, Y., Ishiguro, K., and Watanabe, Y. (2010). Phosphorylation of mammalian Sgo2 by Aurora B recruits PP2A and MCAK to centromeres. Genes Dev. 24, 2169-2179. doi: 10.1101/gad.1945310

Tatsuka, M., Katayama, H., Ota, T., Tanaka, T., Odashima, S., Suzuki, F., et al. (1998). Multinuclearity and increased ploidy caused by overexpression of the aurora- and Ipl1-like midbody-associated protein mitotic kinase in human cancer cells. Cancer Res. 58, 4811-4816.

Tavormina, P. A., Côme, M. G., Hudson, J. R., Mo, Y. Y., Beck, W. T., and Gorbsky, G. J. (2002). Rapid exchange of mammalian topoisomerase II alpha at kinetochores and chromosome arms in mitosis. J. Cell Biol. 158, 23-29. doi: $10.1083 /$ jcb. 200202053

Taylor, S. S., Ha, E., and McKeon, F. (1998). The human homologue of Bub3 is required for kinetochore localization of Bubl and a Mad3/Bub1-related protein kinase. J. Cell Biol. 142, 1-11. doi: 10.1083/jcb.142.1.1

Taylor, S. S., Hussein, D., Wang, Y., Elderkin, S., and Morrow, C. J. (2001). Kinetochore localisation and phosphorylation of the mitotic checkpoint components Bub1 and BubR1 are differentially regulated by spindle events in human cells. J. Cell Sci. 114, 4385-4395.

Tedeschi, A., Wutz, G., Huet, S., Jaritz, M., Wuensche, A., Schirghuber, E., et al. (2013). Wapl is an essential regulator of chromatin structure and chromosome segregation. Nature 501, 564-568. doi: 10.1038/nature12471

Thompson, S. L., Bakhoum, S. F., and Compton, D. A. (2010). Mechanisms of chromosomal instability. Curr. Biol. 20, R285-R295. doi: $10.1016 /$ j.cub.2010.01.034

Torres, E. M., Williams, B. R., and Amon, A. (2008). Aneuploidy: cells losing their balance. Genetics 179, 737-746. doi: 10.1534/genetics.108.090878

Trinkle-Mulcahy, L., Andersen, J., Lam, Y. W., Moorhead, G., Mann, M., and Lamond, A. I. (2006). Repo-Man recruits PP1 gamma to chromatin and is essential for cell viability. J. Cell Biol. 172, 679-692. doi: 10.1083/jcb.200508154

Tsukahara, T., Tanno, Y., and Watanabe, Y. (2010). Phosphorylation of the CPC by Cdk1 promotes chromosome bi-orientation. Nature 467, 719-723. doi: $10.1038 /$ nature 09390

Uchida, K. S., Takagaki, K., Kumada, K., Hirayama, Y., Noda, T., and Hirota, T. (2009). Kinetochore stretching inactivates the spindle assembly checkpoint. J. Cell Biol. 184, 383-390. doi: 10.1083/jcb.200811028

Uren, A. G., Beilharz, T., O'Connell, M. J., Bugg, S. J., van Driel, R., Vaux, D. L., et al. (1999). Role for yeast inhibitor of apoptosis (IAP)-like proteins in cell division. Proc. Natl. Acad. Sci. U.S.A. 96, 10170-10175. doi: 10.1073/pnas.96.18.10170

Uren, A. G., Coulson, E. J., and Vaux, D. L. (1998). Conservation of baculovirus inhibitor of apoptosis repeat proteins (BIRPs) in viruses, nematodes, vertebrates and yeasts. Trends Biochem. Sci. 23, 159-162. doi: 10.1016/S0968-0004(98)01198-0

Uren, A. G., Wong, L., Pakusch, M., Fowler, K. J., Burrows, F. J., Vaux, D. L., et al. (2000). Survivin and the inner centromere protein INCENP show similar cell-cycle localization and gene knockout phenotype. Curr. Biol. 10, 1319-1328. doi: 10.1016/S0960-9822(00)00769-7

Vader, G., Kauw, J. J., Medema, R. H., and Lens, S. M. (2006). Survivin mediates targeting of the chromosomal passenger complex to the centromere and midbody. EMBO Rep. 7, 85-92. doi: 10.1038/sj.embor.7400562

Vagnarelli, P., Ribeiro, S., Sennels, L., Sanchez-Pulido, L., de Lima Alves, F., Verheyen, T., et al. (2011). Repo-Man coordinates chromosomal reorganization with nuclear envelope reassembly during mitotic exit. Dev. Cell 21, 328-342. doi: 10.1016/j.devcel.2011.06.020

van der Waal, M. S., Saurin, A. T., Vromans, M. J., Vleugel, M., Wurzenberger, C., Gerlich, D. W., et al. (2012). Mps1 promotes rapid centromere accumulation of Aurora B. EMBO Rep. 13, 847-854. doi: 10.1038/embor.2012.93

Vanoosthuyse, V., Prykhozhij, S., and Hardwick, K. G. (2007). Shugoshin 2 regulates localization of the chromosomal passenger proteins in fission yeast mitosis. Mol. Biol. Cell 18, 1657-1669. doi: 10.1091/mbc.E06-10-0890

Varier, R. A., Outchkourov, N. S., de Graaf, P., van Schaik, F. M., Ensing, H. J., Wang, F., et al. (2010). A phospho/methyl switch at histone $\mathrm{H} 3$ regulates TFIID association with mitotic chromosomes. EMBO J. 29, 3967-3978. doi: 10.1038/emboj.2010.261

Villa, F., Capasso, P., Tortorici, M., Forneris, F., de Marco, A., Mattevi, A., et al. (2009). Crystal structure of the catalytic domain of Haspin, an atypical kinase implicated in chromatin organization. Proc. Natl. Acad. Sci. U.S.A. 106, 20204-20209. doi: 10.1073/pnas.0908485106 
Vleugel, M., Omerzu, M., Groenewold, V., Hadders, M. A., Lens, S. M., and Kops, G. J. (2015). Sequential multisite phospho-regulation of KNL1-BUB3 interfaces at mitotic kinetochores. Mol. Cell 57, 824-835. doi: 10.1016/j.molcel.2014.12.036

Vleugel, M., Tromer, E., Omerzu, M., Groenewold, V., Nijenhuis, W., Snel, B., et al. (2013). Arrayed BUB recruitment modules in the kinetochore scaffold KNL1 promote accurate chromosome segregation. J. Cell Biol. 203, 943-955. doi: $10.1083 /$ jcb.201307016

Wan, X., O'Quinn, R. P., Pierce, H. L., Joglekar, A. P., Gall, W. E., DeLuca, J. G., et al. (2009). Protein architecture of the human kinetochore microtubule attachment site. Cell 137, 672-684. doi: 10.1016/j.cell.2009.03.035

Wang, F., Dai, J., Daum, J. R., Niedzialkowska, E., Banerjee, B., Stukenberg, P. T., et al. (2010). Histone H3 Thr-3 phosphorylation by Haspin positions Aurora B at centromeres in mitosis. Science 330, 231-235. doi: 10.1126/science.1189435

Wang, F., Ulyanova, N. P., Daum, J. R., Patnaik, D., Kateneva, A. V., Gorbsky, G. J., et al. (2012). Haspin inhibitors reveal centromeric functions of Aurora B in chromosome segregation. J. Cell Biol. 199, 251-268. doi: 10.1083/jcb.201205106

Wang, F., Ulyanova, N. P., van der Waal, M. S., Patnaik, D., Lens, S. M., and Higgins, J. M. (2011). A positive feedback loop involving Haspin and Aurora B promotes CPC accumulation at centromeres in mitosis. Curr. Biol. 21, 1061-1069. doi: 10.1016/j.cub.2011.05.016

Watanabe, Y. (2010). Temporal and spatial regulation of targeting aurora B to the inner centromere. Cold Spring Harb. Symp. Quant. Biol. 75, 419-423. doi: $10.1101 / \mathrm{sqb} .2010 .75 .035$

Welburn, J. P., Vleugel, M., Liu, D., Yates, J. R. III., Lampson, M. A., Fukagawa, T., et al. (2010). Aurora B phosphorylates spatially distinct targets to differentially regulate the kinetochore-microtubule interface. Mol. Cell 38, 383-392. doi: 10.1016/j.molcel.2010.02.034

Wheelock, M. S., Wynne, D. J., Tseng, B. S., and Funabiki, H. (2017). Dual recognition of chromatin and microtubules by INCENP is important for mitotic progression. J. Cell Biol. 216, 925-941. doi: 10.1083/jcb.201609061

Williams, S. J., Abrieu, A., and Losada, A. (2017). Bub1 targeting to centromeres is sufficient for Sgol recruitment in the absence of kinetochores. Chromosoma 126, 279-286. doi: 10.1007/s00412-016-0592-7

Xie, J., Wooten, M., Tran, V., Chen, B. C., Pozmanter, C., Simbolon, C., et al. (2015). Histone H3 threonine phosphorylation regulates asymmetric histone inheritance in the Drosophila male germline. Cell 163, 920-933. doi: 10.1016/j.cell.2015.10.002

Xu, P., Raetz, E. A., Kitagawa, M., Virshup, D. M., and Lee, S. H. (2013). BUBR1 recruits $\mathrm{PP} 2 \mathrm{~A}$ via the $\mathrm{B} 56$ family of targeting subunits to promote chromosome congression. Biol. Open 2, 479-486. doi: 10.1242/bio.20134051

Xu, Z., Ogawa, H., Vagnarelli, P., Bergmann, J. H., Hudson, D. F., Ruchaud, S., et al. (2009). INCENP-aurora B interactions modulate kinase activity and chromosome passenger complex localization. J. Cell Biol. 187, 637-653. doi: $10.1083 /$ jcb. 200906053
Yamagishi, Y., Honda, T., Tanno, Y., and Watanabe, Y. (2010). Two histone marks establish the inner centromere and chromosome bi-orientation. Science 330, 239-243. doi: 10.1126/science.1194498

Yamagishi, Y., Yang, C. H., Tanno, Y., and Watanabe, Y. (2012). MPS1/Mph1 phosphorylates the kinetochore protein $\mathrm{KNL} 1 / \mathrm{Spc} 7$ to recruit SAC components. Nat. Cell Biol. 14, 746-752. doi: 10.1038/ncb2515

Yamanaka, Y., Heike, T., Kumada, T., Shibata, M., Takaoka, Y., Kitano, A., et al. (2008). Loss of Borealin/DasraB leads to defective cell proliferation, p53 accumulation and early embryonic lethality. Mech. Dev. 125, 441-450. doi: $10.1016 /$ j.mod.2008.01.011

Yoon, H. J., and Carbon, J. (1999). Participation of Birlp, a member of the inhibitor of apoptosis family, in yeast chromosome segregation events. Proc. Natl. Acad. Sci. U.S.A. 96, 13208-13213. doi: 10.1073/pnas.96.23.13208

Yoshida, M. M., Ting, L., Gygi, S. P., and Azuma, Y. (2016). SUMOylation of DNA topoisomerase $\mathrm{II} \alpha$ regulates histone $\mathrm{H} 3$ kinase Haspin and $\mathrm{H} 3$ phosphorylation in mitosis. J. Cell Biol. 213, 665-678. doi: 10.1083/jcb.201511079

Yue, Z., Carvalho, A., Xu, Z., Yuan, X., Cardinale, S., Ribeiro, S., et al. (2008). Deconstructing Survivin: comprehensive genetic analysis of Survivin function by conditional knockout in a vertebrate cell line. J. Cell Biol. 183, 279-296. doi: $10.1083 /$ jcb.200806118

Zhang, Q., Lin, G., Gu, Y., Peng, J., Nie, Z., Huang, Y., et al. (2009). Borealin is differentially expressed in ES cells and is essential for the early development of embryonic cells. Mol. Biol. Rep. 36, 603-609. doi: 10.1007/s11033-008-9220-9

Zhang, X. D., Goeres, J., Zhang, H., Yen, T. J., Porter, A. C., and Matunis, M. J. (2008). SUMO-2/3 modification and binding regulate the association of CENPE with kinetochores and progression through mitosis. Mol. Cell 29, 729-741. doi: 10.1016/j.molcel.2008.01.013

Zhou, L., Liang, C., Chen, Q., Zhang, Z., Zhang, B., Yan, H., et al. (2017). The N-terminal non-kinase-domain-mediated binding of haspin to Pds5B protects centromeric cohesion in mitosis. Curr. Biol. 27, 992-1004. doi: 10.1016/j.cub.2017.02.019

Zhou, L., Tian, X., Zhu, C., Wang, F., and Higgins, J. M. (2014). Polo-like kinase-1 triggers histone phosphorylation by Haspin in mitosis. EMBO Rep. 15, 273-281. doi: 10.1002/embr.201338080

Conflict of Interest Statement: The authors declare that the research was conducted in the absence of any commercial or financial relationships that could be construed as a potential conflict of interest.

Copyright (C) 2017 Hindriksen, Lens and Hadders. This is an open-access article distributed under the terms of the Creative Commons Attribution License (CC BY). The use, distribution or reproduction in other forums is permitted, provided the original author(s) or licensor are credited and that the original publication in this journal is cited, in accordance with accepted academic practice. No use, distribution or reproduction is permitted which does not comply with these terms. 